\title{
Indices of the fullerenes reactivity
}

\author{
Denis Sh. Sabirov, ${ }^{a *}$ Ramil G. Bulgakov, ${ }^{a}$ and Sergey L. Khursan ${ }^{b}$ \\ ${ }^{a}$ Physical Chemistry Problems Laboratory, Institute of Petrochemistry and Catalysis of Russian \\ Academy of Sciences, 141 Prospekt Oktyabrya, 450075 Ufa, Russia \\ ${ }^{b}$ Chemical Kinetics Laboratory, Institute of Organic Chemistry, Ufa Scientific Centre of Russian \\ Academy of Sciences, 71 Prospekt Oktyabrya, 450054 Ufa, Russia \\ E-mail: diozno@mail.ru
}

This paper is dedicated to prof. Usein M. Dzhemilev on the occasion of his $65^{\text {th }}$ birthday

DOI: http://dx.doi.org/10.3998/ark.5550190.0012.816

\begin{abstract}
The review summarizes articles devoted to studies of fullerenes reactivity by quantum-chemical methods using of diverse reactivity indices, e.g. heats of reactions, activation energies, spin densities, pyramidality angles. Among them we can elect both approaches that have been used for the other organic compounds earlier (e.g., comparative bond orders analysis) and approaches being used for fullerenes and nanotubes only (curvature and polarizability indices).The prognostic potential of the mentioned approaches as well the trends of their application and further development are considered.
\end{abstract}

Keywords: Fullerenes, reactivity, theoretical methods of investigation, indices of reactivity, heat of reaction

\section{Table of Contents}

1. Introduction

2. Discussion

2.1 Quantum chemical calculations of thermodynamic and kinetic parameters of reactions of fullerenes

2.2 The estimation of fullerene reactivity using population analysis

2.3 The estimation of fullerene reactivity via the analysis of molecular orbitals

2.4 The estimation of fullerene reactivity by indices based on the fullerenes structure

3. Conclusion

4. Acknowledgements

5. References 


\section{Introduction}

Theoretical methods of investigation took a special place in the fullerene science. Particularly, it is caused with the fact that the first works devoted to fullerenes were essentially the prognoses of stability and electronic properties of the polyhedral molecules constructed with carbon atoms.

Since $\mathrm{C}_{60}$ and $\mathrm{C}_{70}$ fullerenes have been discovered and the techniques of those production in sufficient amounts for studies of their synthetic transformations, the topics of theoretical researches (presumably, quantum chemical calculations) shifted to the investigations of $\mathrm{C}_{60}$ and $\mathrm{C}_{70}$ structure and prediction of the most probable reaction sites in their molecules. Also estimation of the stability of fullerene derivatives which can be successfully used in medicine, nanotechnologies, industry etc. have been studied in terms of various theoretical approaches.

In contrast to classical representatives of the fullerene family $\left(\mathrm{C}_{60}\right.$ and $\left.\mathrm{C}_{70}\right)$, the reactivity of recently discovered and less available higher (e.g., $\left.\mathrm{C}_{76}, \mathrm{C}_{78}, \mathrm{C}_{82}, \mathrm{C}_{84}\right)$ and small fullerenes $\left(\mathrm{C}_{20}\right.$, $\mathrm{C}_{36}, \mathrm{C}_{50}$ ) has been poorly studied. In this context, various theoretical methods for prognosis of chemical properties of these compounds are developed. To analyze various theoretical approaches to study of the fullerenes reactivity, we divided them in four groups:

1. The estimation of the possibility of reaction with fullerene based on the heat effect (and/or activation energy) of reaction.

2. The estimation of fullerene reactivity using population analysis.

3. The estimation of fullerene reactivity via the analysis of molecular orbitals.

4. The estimation of fullerene reactivity by indices based on the fullerenes structure (bond lengths, pyramidality angles, curvature).

\section{Discussion}

\subsection{Quantum chemical calculations of thermodynamic and kinetic parameters of reactions of fullerenes}

The widespread approach to theoretical description of fullerenes' chemical behavior is based on the calculated heats and/or activation energies for alternative reaction modes. Many studies on synthesis and structural peculiarities of products of various $\mathrm{C}_{60}$ and $\mathrm{C}_{70}$ chemical transformations are accompanied by theoretical estimations of this kind. However, it has some disadvantages. First of all, heat of reaction not always represents the reaction mechanism and characterizes the stability of products. The second, calculation of activation energies (and sometimes of heat effects) is conjugated with several difficulties caused by excessive needs of computational resources for quantum chemical studies. In addition, theoretical studies of higher fullerenes reactivity deals with the greater number of reaction sites to be analyzed: e.g., there are 15 types of 6.6 bonds in $\mathrm{C}_{76}$ fullerene. ${ }^{1}$ Third, thermodynamic and activation parameters characterize, first of all, chemical processes which compound takes part in but not a compound as itself. That is why in the paper we present several works of this kind without the detailed exploration. 
Thus, the comparison of heat effects of addition (to 6.6 or to 5.6 bonds) calculated by PBE density functional with various basis sets has been shown the most probable addition of $\mathrm{O}, \mathrm{O}_{2}$, $\mathrm{O}_{3}, \mathrm{NO}, \mathrm{N}_{2}, \mathrm{CH}_{4}, \mathrm{NH}_{3}, \mathrm{H}_{2} \mathrm{O}, \mathrm{C}_{60}$ to a 6.6 bond of $\mathrm{C}_{60} .^{2}$ This quantum chemical method has been used to study potential energy surfaces of several routes of ozone addition to $\mathrm{C}_{60}$ and $\mathrm{C}_{70}$ fullerenes and allowed to discover that the first stage of $\mathrm{C}_{60} / \mathrm{C}_{70}$ interaction with ozone is the formation of prereactionary complexes which then convert into the final products of the addition (primary ozonides). ${ }^{3}$ The addition of the second $\mathrm{O}_{3}$ molecule to $\mathrm{C}_{60} \mathrm{O}_{3}$ primary ozonide can occur to any remained 6.6 bond of $\mathrm{C}_{60} \mathrm{O}_{3}$ that should lead to eight isomeric $\mathrm{C}_{60}\left(\mathrm{O}_{3}\right)_{2}$ : heats of $\mathrm{O}_{3}$ addition to $\mathrm{C}_{60} \mathrm{O}_{3}$ calculated by $\mathrm{PBE} / 3 \mathrm{z}$ method have been found to be close $\left(\Delta H_{\mathrm{r}}{ }^{\circ}=\right.$ $\left.-125.2 \ldots-141.5 \mathrm{~kJ} \mathrm{~mol}^{-1}\right){ }^{4}$

Initial steps of $\mathrm{C}_{60}$ interaction with $\mathrm{Me} \bullet$ and $\mathrm{MeO}_{2} \bullet$ (leading to respective fullerenyl radicals) have been also studied by $\mathrm{PBE} / 3 \mathrm{z}$ method: ${ }^{5}$

$$
\begin{aligned}
& \mathrm{Me} \bullet+\mathrm{C}_{60} \rightarrow \mathrm{MeC}_{60} \bullet \\
& \mathrm{MeO}_{2} \bullet+\mathrm{C}_{60} \rightarrow \mathrm{MeO}_{2} \mathrm{C}_{60} \bullet
\end{aligned}
$$

Addition of methyl radical to $\mathrm{C}_{60}$ is characterized with the lower activation energy $(11.3 \mathrm{~kJ}$ $\mathrm{mol}^{-1}$ ) in comparison with the reaction of $\mathrm{MeO}_{2} \bullet$ addition $\left(13.5 \mathrm{~kJ} \mathrm{~mol}^{-1}\right)$. This fact should be taken into account in kinetic analysis of competitive reactions of radical addition to $\mathrm{C}_{60}$.

Conclusions about the preference of addition to 6.6 bonds of $\mathrm{C}_{60}$ fullerene have been done upon the AM1 semiempirical studies on the reaction mechanisms of ozone ${ }^{6}$ and 2,3dimethylidenbicyclo[2.2.2] octane addition to $\mathrm{C}_{60} .{ }^{7}$ The analogous scheme has been applied to the $\mathrm{C}_{60}$ reactions with methyl azide ${ }^{8}$ and azomethine ylides bearing the biologically active 1,4dihydropyridine ring. ${ }^{9}$

Reaction pathways of 1,3-dipolar addition of diazomethane, nitryl oxide and nitron to $\mathrm{C}_{60}$ leading to 6.6 closed, 6.6 open, 5.6 closed and 5.6 open adducts have been investigated by B3LYP/6-31G(d,p) and AM1 methods. ${ }^{10}$ Calculations showed that processes of the formation of 5.6 closed and 6.6 open adducts are endothermic while formations of 5.6 open and 6.6 closed are exothermic. The formation of 6.6 closed adducts which should occur via concerted mechanism, is the most favorable thermodynamically and kinetically.

The products of reaction between buthylamine and $\mathrm{C}_{60}$ have been studied by dielectric polarization method and Kerr electro-optic effect (Scheme 1). ${ }^{11}$
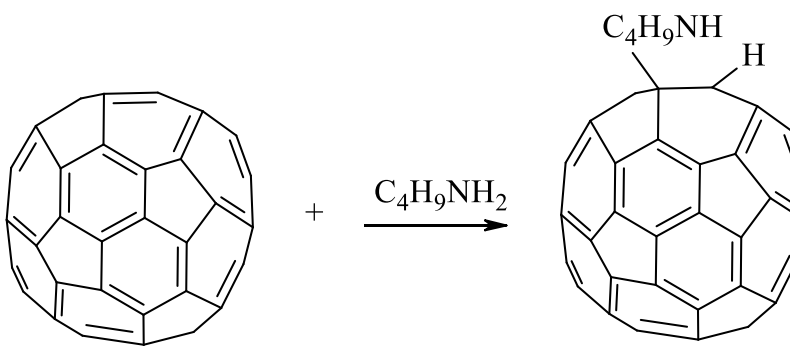

$+\stackrel{\mathrm{C}_{4} \mathrm{H}_{9} \mathrm{NH}_{2}}{\longrightarrow}$

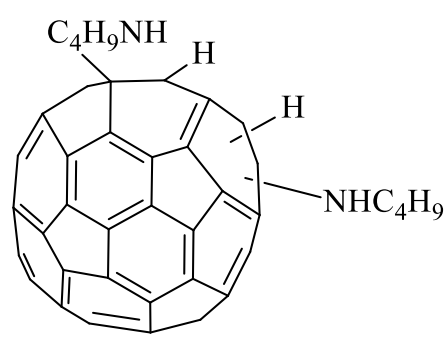

\section{Scheme 1}


Heats of formation of $\mathrm{C}_{60}$ adducts with various number of added buthylamine molecules have been calculated by semiempirical PM3 method. The scheme of addition proposed the formation of different polar (structures 2-1, 3-1, 4-1) and nonpolar (structures 2-2, 3-2, 4-2) regioisomers has been considered (Figure 1). Heats of formation of polar and nonpolar isomers with the same number of addends are close. So, authors ${ }^{11}$ concluded the equiprobability of their formation upon the reaction under study.
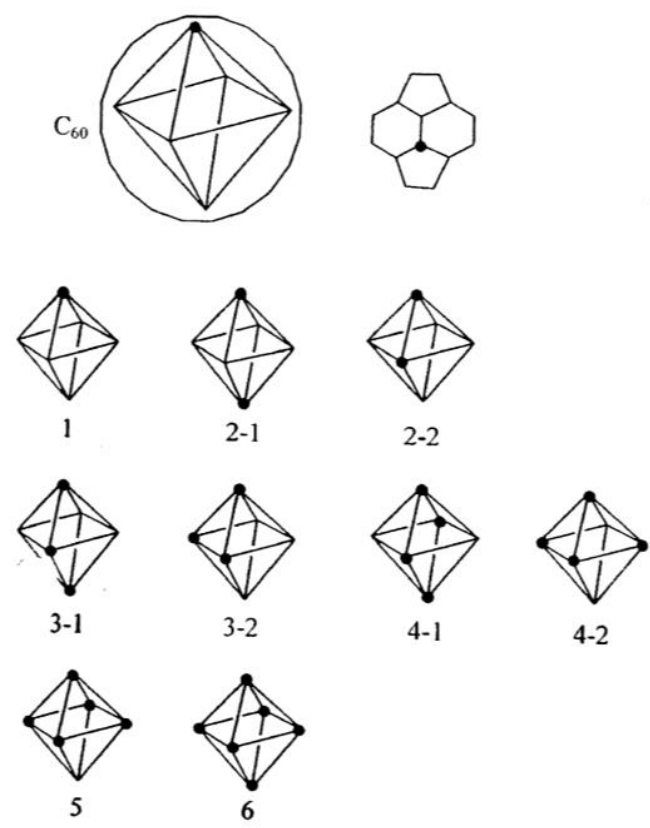

Figure 1. Regioselective scheme of addition of the same addends to $\mathrm{C}_{60}{ }^{11}$

The quantum chemical calculation of heats of reactions leading to fullerene bisadducts became common. E.g., the comparison of the heats of eight possible routes of carbene addition to fullerenocyclopropane 1 (Scheme 2) has shown the equiprobable formation of all possible $\mathrm{C}_{60}[\mathrm{C}(\mathrm{Me}) \mathrm{COOEt}]_{2}$ isomers. $^{12}$

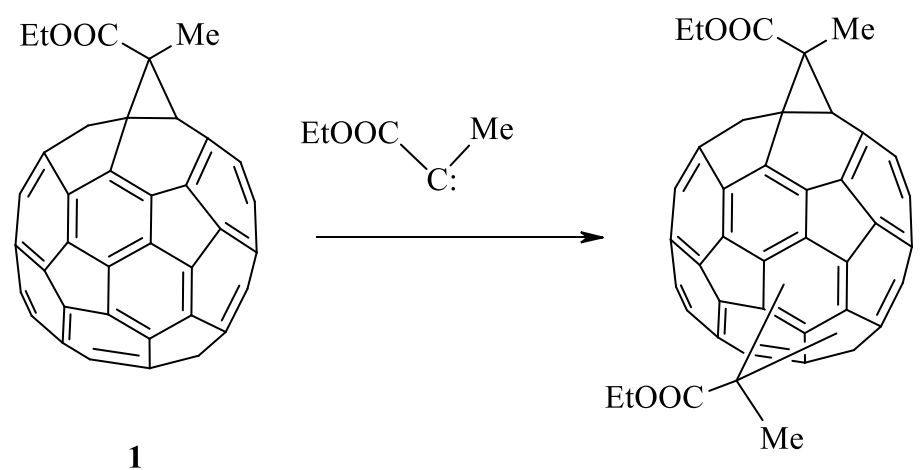

\section{Scheme 2}


Calculated heats of reactions have been successfully applied to the analysis of the routes of chemiluminescence emitters generation upon $\mathrm{C}_{60}$ and $\mathrm{C}_{70}$ ozonolysis. A decrease in the intensity of chemiluminescence upon $\mathrm{C}_{60}$ ozonolysis in the presence of protic substrates $\mathrm{ROH}$ (typical carbonyl oxides scavengers) has been detected that proves the generation of oxofullerenecarbonyl oxides (OFCO) by fullerene ozonolysis. ${ }^{13}$ Heats of the further both bimolecular and monomolecular transformations of the simplest oxo[60]fullerenecarbonyl oxide 2 are sufficient for excitation of $\mathrm{C}_{60}$ oxy derivatives (the measured energy of excitation equals to $191.6 \mathrm{~kJ} \mathrm{~mol}^{-1}$ ) according to the Scheme 3 (calculated heat effects are given in $\mathrm{kJ} \mathrm{mol}^{-1}$; PBE/3z method).

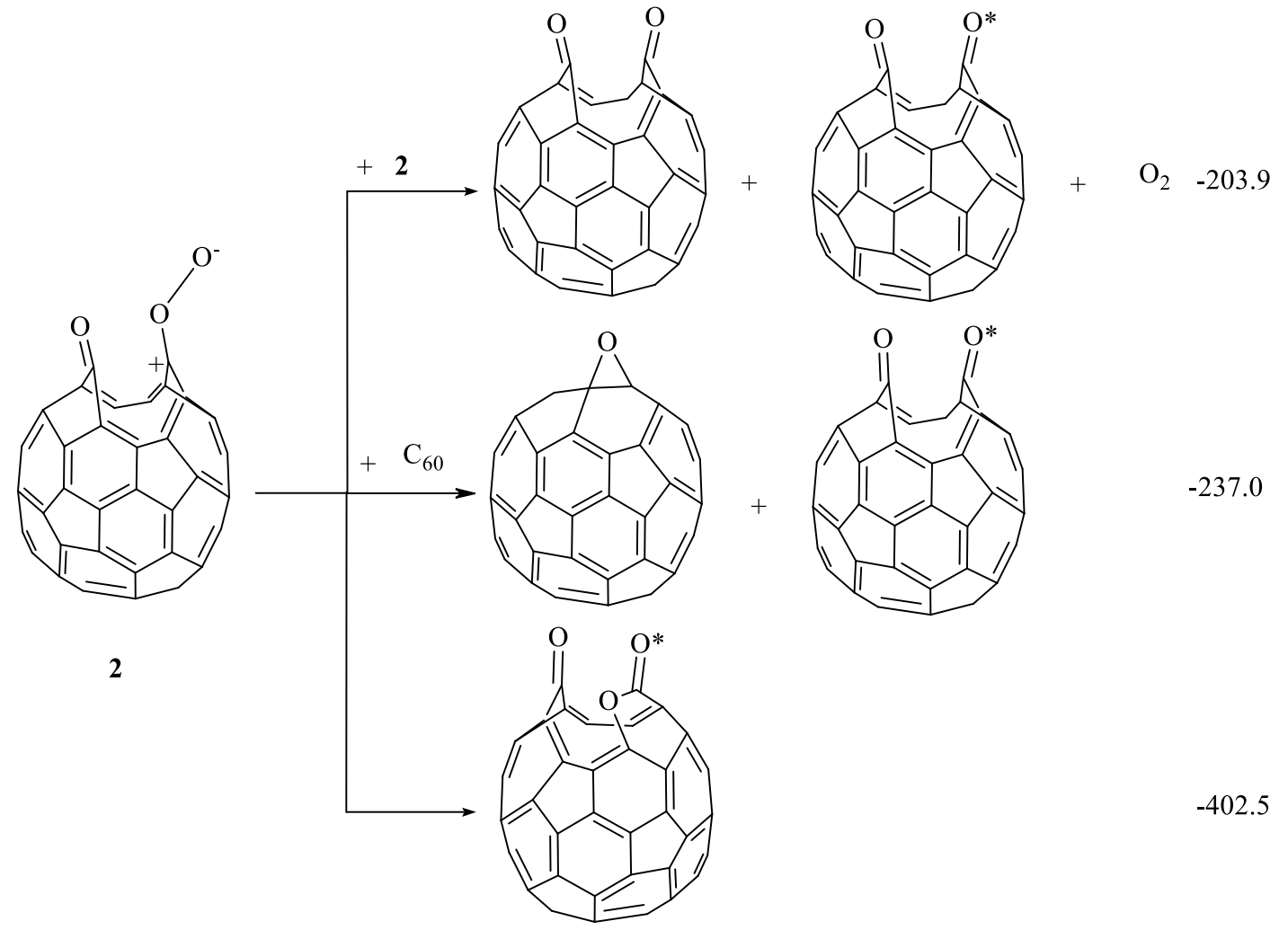

\section{Scheme 3}

Later ${ }^{14}$ chemiluminescence studies showed that OFCO generated by $\mathrm{C}_{60}$ ozonolysis (60OFCO, 2) and those generated by analogous reaction of $\mathrm{C}_{70}(\boldsymbol{c c}-70-\mathrm{OFCO}-\mathbf{3}, \boldsymbol{a b}-70-\mathrm{OFCO}-\mathbf{4}$, $\boldsymbol{b} \boldsymbol{a}-70-\mathrm{OFCO}-\mathbf{5})$ are characterized with the different reactivity towards $\mathrm{ROH}$ and the same one towards Py.

This experimental fact has been proven by theoretical calculation of heats of OFCOs reactions with $\mathrm{MeOH}$ and $\mathrm{Py}$ (Scheme 4; calculated exothermic heat effects are given in $\mathrm{kJ}$ $\mathrm{mol}^{-1}$; PBE/3z method). Calculations demonstrate the lower reactivity of $\boldsymbol{c c}$-70-OFCO 3 towards methanol. The performed quantum-topological analysis has elucidated that in contrast to another OFCOs the structure of $\boldsymbol{c} c$-70-OFCO is stabilized by the interaction of terminal oxygen atoms of carbonyl group and carbonyl oxide fragment $\left(\mathrm{C}^{+}-\mathrm{OO}^{-} \ldots \mathrm{O}=\mathrm{C}\right)$. Thus, the structure and properties 
of the unstable products and intermediates of fullerenes reactions can differ in spite of the same contents of the stable products of $\mathrm{C}_{60}$ and $\mathrm{C}_{70}$ transformations.

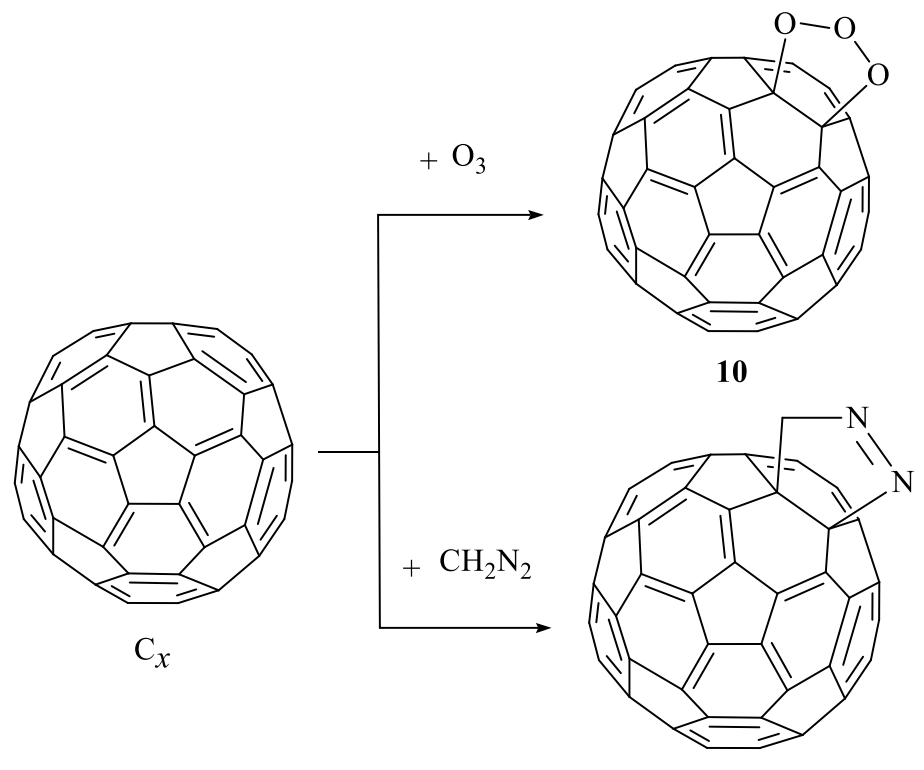

11

Besides the heat of reaction, the change in total energy can be used as a thermodynamic parameter characterizing the possibility of reaction. For example, for theoretical study on the formation of fullerenes derivatives $\mathrm{C}_{60} \mathrm{X}$ and $\mathrm{C}_{70} \mathrm{X}$, the approach based on the estimation of two items in the total energy of chemically modified system has been worked out. ${ }^{15}$ The first of them characterizes the change of electronic energy upon chemical reaction with the pristine geometry of a carbon cluster, and the second shows the change of the energy due to the deformation of a carbon cluster when addends are chemically bonded with a fullerene. This approach has been used on the level of Hückel method and allowed, e.g., to compare the possibilities of generations of 6.6 and 5.6 adducts in the addition of molecular and atomic oxygen to fullerenes.

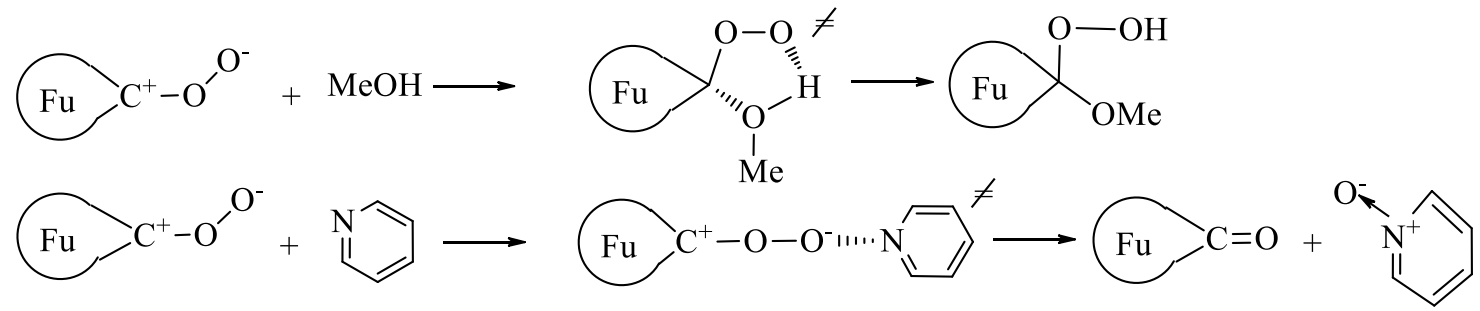

$\mathrm{Fu}$ - transformed fullerene moiety

\begin{tabular}{ccccc}
\hline Reaction & $\mathbf{2}$ & $\mathbf{3}$ & $\mathbf{4}$ & $\mathbf{5}$ \\
\hline$(1)$ & 47.7 & 21.9 & 53.2 & 43.5 \\
$(2)$ & 205.1 & 198.4 & 203.7 & 204.8 \\
\hline
\end{tabular}

\section{Scheme 4}


For comparative study of $\mathrm{C}_{50}\left(D_{5 h}\right), \mathrm{C}_{60}\left(I_{h}\right)$ and $\mathrm{C}_{70}\left(D_{5 h}\right)$ reactivities, the changes in total energy upon the approaching of carbon atom to reaction site in a fullerene molecule have been calculated by several density functional theory methods. ${ }^{16}$ The calculations showed that reaction sites in $\mathrm{C}_{50}\left(D_{5 h}\right)$ and $\mathrm{C}_{70}\left(D_{5 h}\right)$ are characterized with higher reactivity than those in $\mathrm{C}_{60}$.

Thermodynamics studies of fullerene derivatives became indispensable part of the screening the materials for hydrogen accumulators. Here we should note the recent theoretical study ${ }^{17}$ of endohedral complexes of $\mathrm{C}_{60}$ showed the thermodynamic stability of both $\mathrm{H}_{2} @ \mathrm{C}_{60}$ and $2 \mathrm{H}_{2} @ \mathrm{C}_{60}$ by DFT and MP2 calculations. The combined clusters of fullerenes and metals are another type of compounds which are applicable for hydrogen storage. Recent DFT studies have shown that the behavior of alkali metals on the $\mathrm{C}_{60}$ surface differs: lithium atoms are found to coat homogenously the fullerene while sodium atoms form the bonds with each other (Figure 2). ${ }^{18}$ So, the arrangement of Li atoms seems more favorable for the hydrogen storage than that of sodium. Buckminsterfullerene decorated with $32 \mathrm{Ca}$ atoms on each of its 20 hexagonal and 12 pentagonal faces, as shown theoretically, ${ }^{19}$ is extremely stable. $\mathrm{C}_{60} \mathrm{Ca}_{32}$ cluster can absorb up to $62 \mathrm{H}_{2}$ molecules in two layers. Not only hydrogen molecules can be encapsulated in the fullerene cage. For example, the trapping polynitrogen clusters inside $\mathrm{C}_{60}$ is possible. DFT calculations ${ }^{20}$ shows that a maximum of 13 nitrogen atoms can be encapsulated in $\mathrm{C}_{60}$ without distorting the $\mathrm{C}_{60}$ significantly.
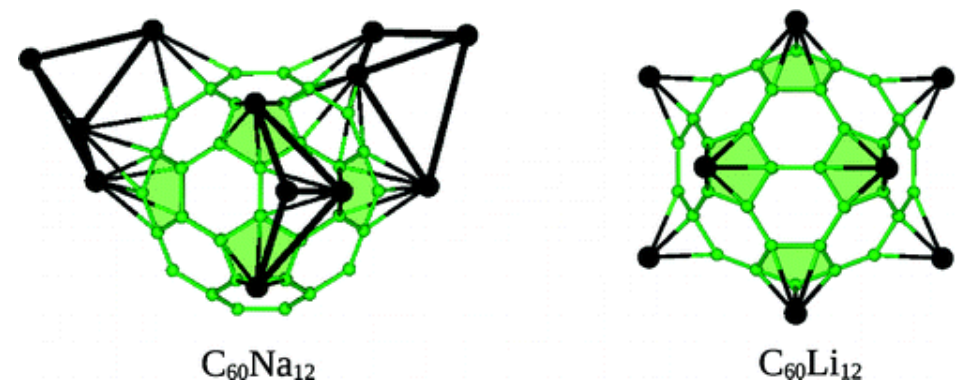

Figure 2. Equilibrium structures of alkali- $\mathrm{C}_{60}$ nanoclusters. ${ }^{18}$

At last, we should mention two novel branches of the thermodynamics and stability of hypothetical fullerene-like structures.

First of them is devoted to the search of the thermodynamically stable structures among the functionalized non-classical fullerenes (fullerenes which do not obey the isolated pentagon rule or have in the structure heptagons). For example, the geometrical structures, electronic properties, and stabilities of unconventional fullerene derivatives $\mathrm{C}_{64} \mathrm{X}_{6}(\mathrm{X}=\mathrm{H}, \mathrm{F}, \mathrm{Cl})$ have been systematically studied by the first principle calculations based on the DFT. ${ }^{21}$ It has been shown that the fullerene derivatives $1911(2)-\mathrm{C}_{64} \mathrm{X}_{6}$ generated from the pineapple-shaped $\mathrm{C}_{64} \mathrm{X}_{4}$ are predicted to possess the lowest energies. To analyze the ways of the $\mathrm{C}_{64} \mathrm{X}_{6}$ synthesis, the thermochemistry $\mathrm{C}_{64} \mathrm{X}_{4}+\mathrm{X}_{2} \rightarrow \mathrm{C}_{64} \mathrm{X}_{6}$ of reactions has been studied. The NMR and IR spectra of several compounds have been calculated to facilitate future experimental identification. 
The structures and stability of fullerene derivatives have been obtained from the results of DFT calculations performed on 6 non-classical and 306 classical isomers of $\mathrm{C}_{58} \mathrm{X}_{18}(\mathrm{X}=\mathrm{H}, \mathrm{F}$, Cl). ${ }^{22}$ The calculated results demonstrated that the most energetically stable isomers of $\mathrm{C}_{58} \mathrm{H}_{18}$ and $\mathrm{C}_{58} \mathrm{~F}_{18}$ are heptagon-containing non-classical structures (Figure 3). However, for the $\mathrm{X}=\mathrm{Cl}$ series of isomers, the classical $1156-\mathrm{C}_{58} \mathrm{Cl}_{18}$ isomer is predicted to be over $142 \mathrm{~kJ} \mathrm{~mol}^{-1}$ energetically stable than the non-classical structures. Structural analysis demonstrates that the size of added atoms plays an important role in determining the structures and stability of $\mathrm{C}_{58} \mathrm{X}_{18}$ $(\mathrm{X}=\mathrm{H}, \mathrm{F}, \mathrm{Cl})$.

The second branch of the thermodynamics studies of hypothetical structures is devoted to the search of the stable endohedral structures based on the non-carbon fullerene-like cages, e.g., golden $\left(\mathrm{X}^{+} @ \mathrm{Au}_{32}, \mathrm{X}=\mathrm{Li}, \mathrm{Na}, \mathrm{K}, \mathrm{Rb}, \mathrm{Cs}\right)^{23}$ or boron fullerenes $\left(\mathrm{La}_{2} @ \mathrm{~B}_{80}, \mathrm{Sc}_{3} \mathrm{~N} @ \mathrm{~B}_{80}\right) .{ }^{24}$

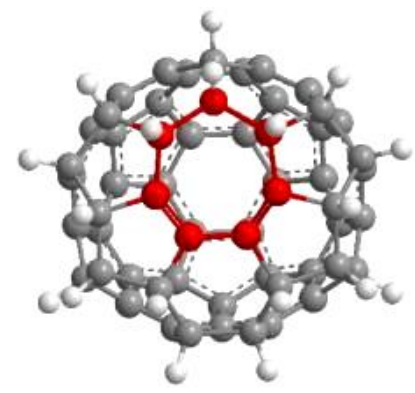

$\mathrm{C}_{58} \mathrm{H}_{18}$ - $\mathrm{Cs}(\mathrm{A})(0.00)$

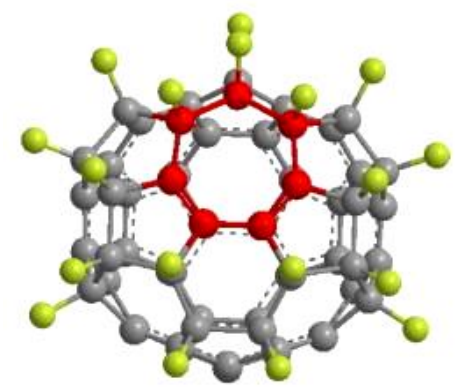

$\mathrm{C}_{58} \mathrm{~F}_{18}-\mathrm{Cs}(\mathrm{A})(0.00)$

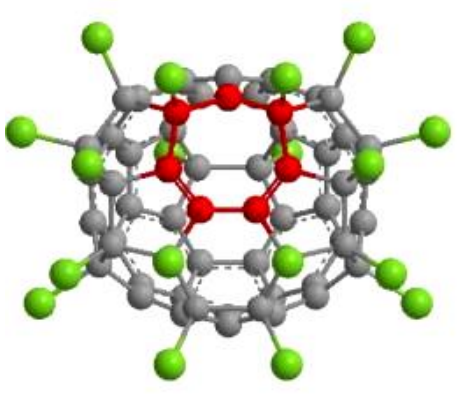

$\mathrm{C}_{58} \mathrm{Cl}_{18}-\mathrm{Cs}(\mathrm{B})(0.00)$

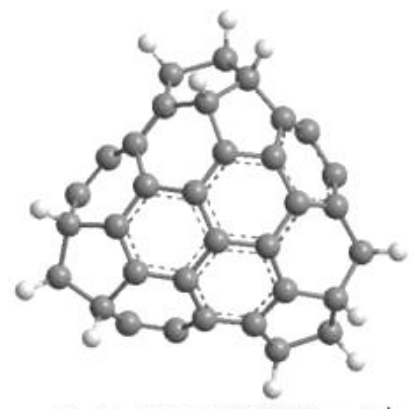

$\mathrm{C}_{58} \mathrm{H}_{18}-315\left(129.8 \mathrm{~kJ} \mathrm{~mol}^{-1}\right)$

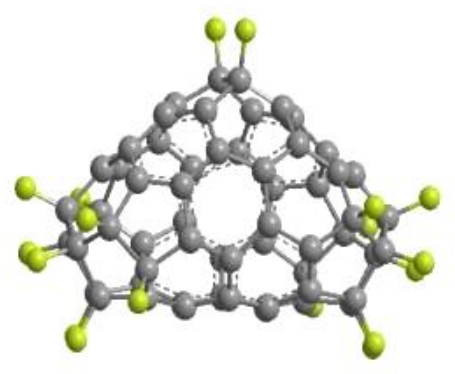

$\mathrm{C}_{58} \mathrm{~F}_{18}-699\left(104.1 \mathrm{~kJ} \mathrm{~mol}^{-1}\right)$

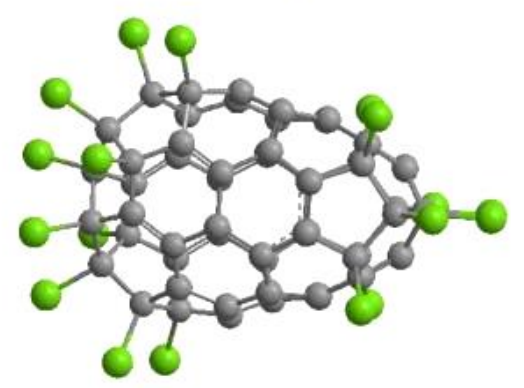

$\mathrm{C}_{58} \mathrm{Cl}_{18}-1156\left(-143.1 \mathrm{~kJ} \mathrm{~mol}^{-1}\right)$

Figure 3. The optimized structures of the lowest-energy classical and non-classical fullerene derivatives $\mathrm{C}_{58} \mathrm{X}_{18}(\mathrm{X}=\mathrm{H}, \mathrm{F}, \mathrm{Cl})$ at the $\mathrm{B} 3 \mathrm{LYP} / 6-31 \mathrm{G} *$ level (relative energies are in the parentheses). ${ }^{22}$ 


\subsection{The estimation of fullerene reactivity using population analysis}

Quantum-chemical investigations of $\mathrm{C}_{60}$ and $\mathrm{C}_{20}$ have been performed long before their experimental discoveries. For example, at the first time the structure of $\mathrm{C}_{60}$ has been appeared as a hypothetical example of three-dimensional aromaticity ${ }^{25}$ (though without any calculations). Later ${ }^{26}$ Hückel method has been applied to study $\mathrm{C}_{60}$ and $\mathrm{C}_{20}$ (named in ${ }^{26}$ carbo-s-icosahedron and carbododecahedron, respectively). Those calculations showed that $\mathrm{C}_{60}$ has a closed electronic shell. The $\pi$-electron model which successfully used to describe the electronic structure of planed polyenes, has been extended for $\mathrm{C}_{60}$.

Strictly speaking, there no $\pi$-electronic system in the polyhedral fullerene molecule because the molecule is not plane, and its surface is close to spherical. Bonds in $\mathrm{C}_{60}$ have been described with the following approach: each carbon atom put three hybrid orbitals and three electrons at the formation of three two-electron localized $\sigma$-bonds with neighboring atoms. The fourth electron is located on the hydrid $\rho$-orbital which is orthogonal to three $\sigma$-orbitals oriented along the bonds with the neighboring atoms (Figure 4).

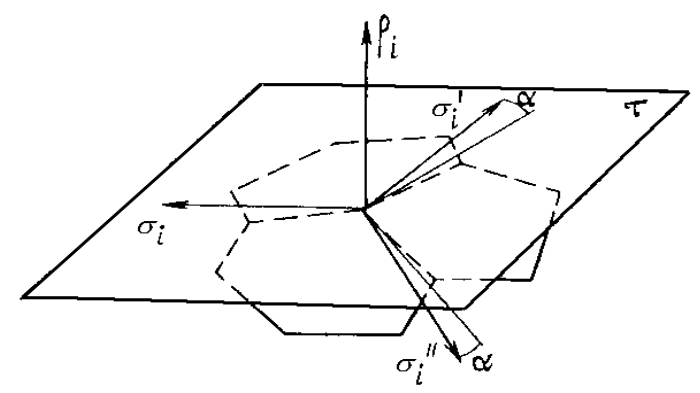

Figure 4. Orbitals of one of the carbon atoms in the $\mathrm{C}_{60}$ molecule. $^{26}$

Three resonant structures 6-8 have been considered for $\mathrm{C}_{60} .{ }^{26}$ Calculated bond orders $(0.60-$ for 6.6 bonds, 0.48 - for 5.6 bonds) allowed to conclude that the structure 6 makes the most significant contribution and 6.6 bonds should display chemical properties which are similar to double bonds of alkenes. Thus, the question about the reactivity of nonequivalent bonds of $\mathrm{C}_{60}$ has been answered with the first paper devoted to quantum-chemical study on this matter.

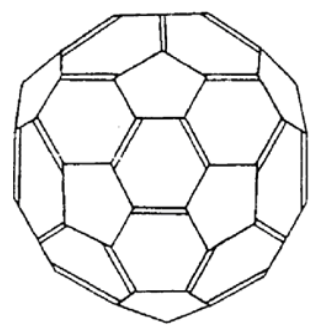

6

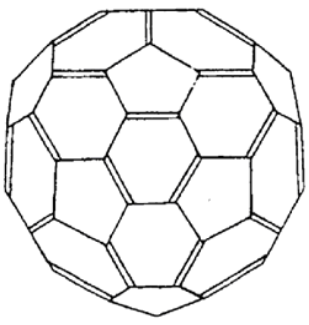

7

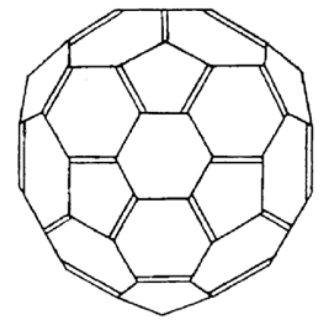

8 
Population analysis has been used in another theoretical approach to study of $\mathrm{C}_{60}$ reactivity: its electronic structure has been investigated in terms of theory of odd electrons. ${ }^{27}$ The 'odd electrons' term has been introduced due to the fact that in $\mathrm{C}_{60}$ the number of valent electrons is greater than the number of covalent bonds on the one. According to ${ }^{27}$ particularly radical character of fullerenes is caused by the presence of effectively unpaired electrons in their molecules. It also causes the singlet instability of Hartree-Fock solutions. Total numbers of effectively unpaired electrons in $\mathrm{C}_{60}$ and $\mathrm{C}_{70}$ equal to 9.84 and 14.40 , respectively ( $20 \%$ of the total number of odd electrons). The same calculations have been preformed for $\mathrm{Si}_{60}$, the silicon analogue of buckminsterfullerene. All of the odd electrons in $\mathrm{Si}_{60}$ have been found to be unpaired that explains the polyradical nature of $\mathrm{Si}_{60}$ and, as consequence, its instability.

Authors of the described approach offer to use the distribution of odd electrons as the measure of fullerenes reactivity. At the moment, the detailed research in terms of the mentioned approach has been performed for $\mathrm{C}_{60}$ only.

Atomic spin densities are perspective for the analysis of reactivity of fullerenyl radicals, the intermediates of radical reactions. E.g., the electronic structure of $\mathrm{RC}_{60}$ radicals $(\mathrm{R}=\mathrm{H}, \mathrm{Et})$ has been studied by PBE/3z method. ${ }^{28}$

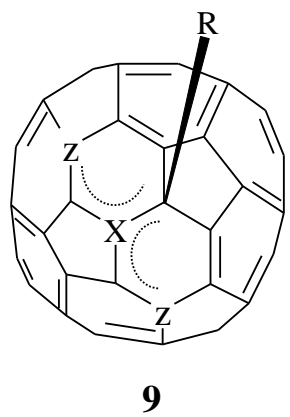

Mulliken population analysis shows the unpaired electron in radicals 9 to be delocalized on the fullerene skeleton. The maximal spin density $\chi$ is concentrated on carbon atoms in $\mathrm{X}$ and $\mathrm{Z}$ positions (e.g., in the case of $\mathrm{R}=\mathrm{Et}, \chi(\mathrm{X})=0.22, \chi(\mathrm{Z})=0.12)$. So, the further addition of radicals to $\mathrm{RC}_{60} \bullet$ should take place preferentially in $\mathrm{X}$ and $\mathrm{Z}$ positions and lead to both 1,2- and 1,4-adducts. The ratio between 1,2- and 1,4-adducts is determined by steric factor: in the case of $\mathrm{H} \cdot$ addition to $\cdot \mathrm{C}_{60} \mathrm{H}$, the formation of $1,2-\mathrm{C}_{60} \mathrm{H}_{2}$ is thermodynamically more favorable while the formation of $1,4-\mathrm{C}_{60} \mathrm{Et}_{2}$ is the dominant reaction mode in the case of more voluminous Et radicals (Scheme 5, calculated exothermic heat effects are given in $\mathrm{kJ} \mathrm{mol}^{-1}$ ). 


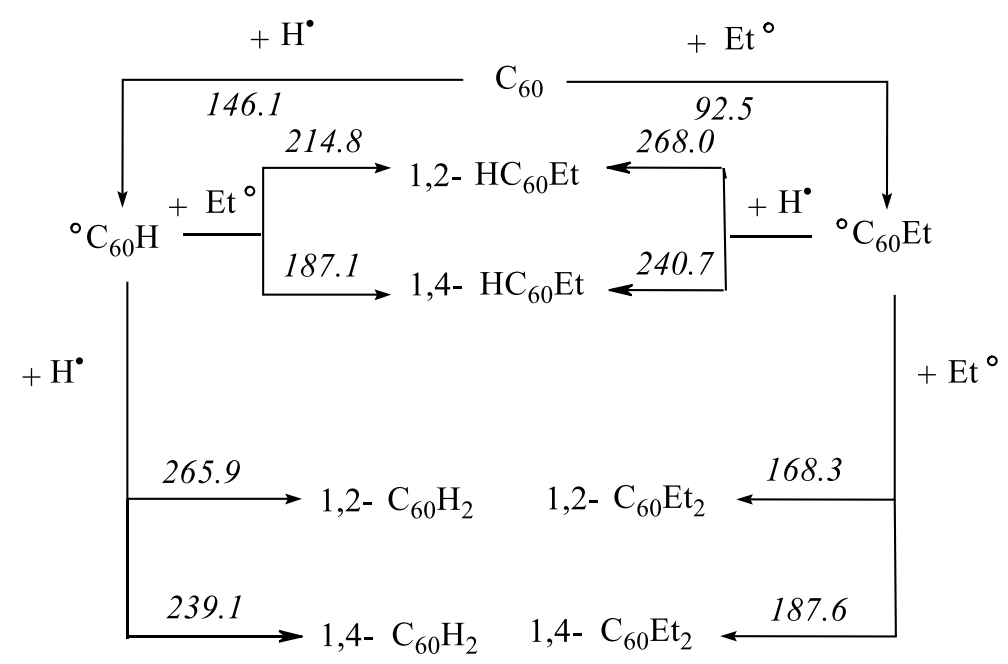

\section{Scheme 5}

\subsection{The estimation of fullerene reactivity via the analysis of molecular orbitals}

The analysis of experimental data on the structure of the products of various reaction of addition to $\mathrm{C}_{60}$ fullerene has been performed. ${ }^{29}$ It shows that much of the studied reactions take place mainly on 6.6 bonds of the fullerene that can be explained in terms of Hückel theory. The description of molecular orbitals allows understanding the principles of the $\mathrm{C}_{60}$ reactivity qualitatively. The analysis of five degenerated HOMOs of $\mathrm{C}_{60}$ (See Figure 5) shows that binding interactions (components of HOMO of the same sign) are localized mainly on the 6.6 bonds while the 5.6 bond are characterized with antibinding interactions (signs of HOMO components localized of the 5.6 bonds differ). In the case of three degenerated LUMOs, another situation is observed: antibinding interactions correspond to 6.6 bonds and binging interactions - to 5.6. Upon occurring of the addition to 6.6 bonds, binding interactions in HOMOs become stronger and antibinding interactions decreases in greater degree than those upon the addition to 5.6 bonds. This approach demonstrated good agreement with experimental data on various reactions of radical and nucleophilic addition. ${ }^{29}$ It has been worked out for $\mathrm{C}_{60}$ and some small fullerenes while the analysis of higher fullerenes in the framework of this approach is too difficult due to greater number of potential reaction sites.

In terms of molecular orbitals, the absolute chemical hardness $\eta$ has been recommended ${ }^{30}$ for comparative estimation of reactivity of fullerenes and aromatic hydrocarbons. It can be found as

$$
\eta=\left(E_{\mathrm{HOMO}}-E_{\mathrm{LUMO}}\right) / 2
$$

where $E_{\mathrm{HOMO}}$ and $E_{\mathrm{LUMO}}$ are energies of HOMO and LUMO. Less reactive molecules are characterized with high $\eta$ values. For example, $\eta$ values for $\mathrm{C}_{60}$ and benzene calculated by Hückel method equal to $-0.378 \beta$ and $-\beta$, respectively that reflects less reactivity of benzene in comparison with $\mathrm{C}_{60}$ in analogous reactions. 
Fukui functions are another index derived from the molecular orbitals analysis. Calculated by BPW91/DNP method, Fukui functions have been used to elucidate the changes in the preferential sites of electrophilic, nucleophilic, and radical attacks on the pristine $\mathrm{C}_{60}$ surface with endohedral doping by $3 \mathrm{~d}$ transition metal atoms. Calculations showed that $\mathrm{C}_{60}$ reactivity changes when it is doped with $\mathrm{Mn}, \mathrm{Fe}, \mathrm{Co}$, or $\mathrm{Ni}$ atoms, whereas there are no significant changes in the preferential reaction sites on the $\mathrm{C}_{60}$ surface upon endohedral doping with $\mathrm{Cu}$ and $\mathrm{Zn}$ atoms. $^{31}$

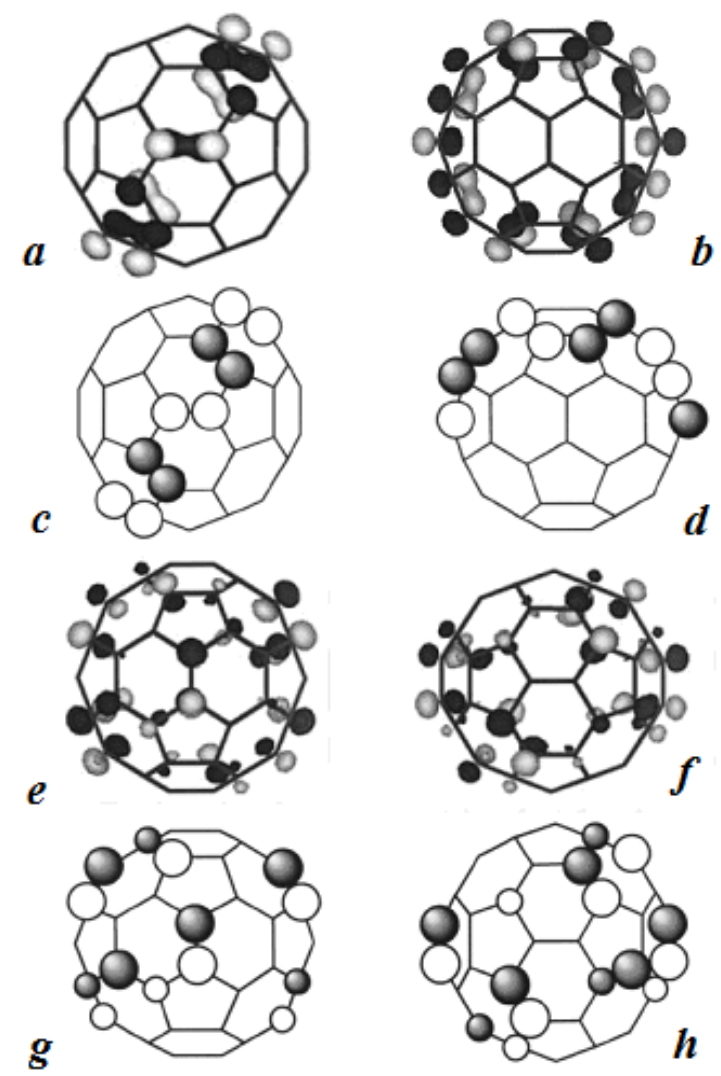

Figure 5. Frontier molecular orbitals of $\mathrm{C}_{60}$ (calculated by PM3 method): $\boldsymbol{a}, \boldsymbol{b}$ - two projections of 5 degenerated HOMOs; $\boldsymbol{c}, \boldsymbol{d}$ - respective projections of schematic representation of exohedral parts of HOMOs; $\boldsymbol{e}, \boldsymbol{f}$ - two projections of 3 degenerated LUMOs; $\boldsymbol{g}, \boldsymbol{h}$ - respective projections of schematic representation of exohedral parts of LUMOs. ${ }^{29}$

The molecular orbital analysis allowed to explain the reactivity of $\mathrm{C}_{50}\left(D_{5 h}\right)$ whose HOMOs and LUMOs are localized on equatorial carbon atoms (Figure 6). ${ }^{32}$ The same atoms, as it noted without any numeric estimations, ${ }^{33}$ are located in the most curved parts of the $\mathrm{C}_{50}$ skeleton. These theoretical prognoses have been confirmed by synthesis and ${ }^{13} \mathrm{C} N M R$ structure determination of chloro-derivative $\mathrm{C}_{50} \mathrm{Cl}_{10}$ having $\mathrm{Cl}$ atoms bonded with carbons of equatorial belf of $\mathrm{C}_{50}$ skeleton (Figure 7). ${ }^{34}$ 


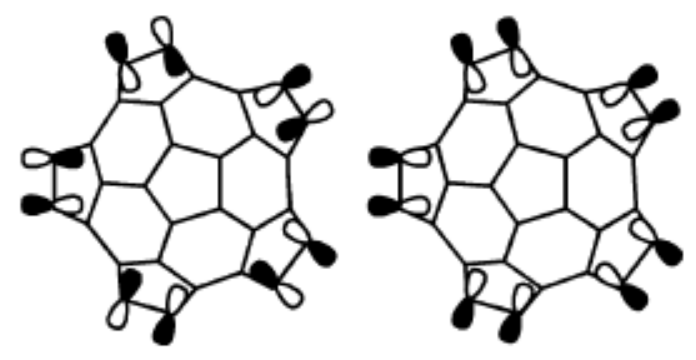

Figure 6. Schematic representation of HOMO (left) and LUMO (right) of $\mathrm{C}_{50}\left(D_{5 h}\right){ }^{33}$

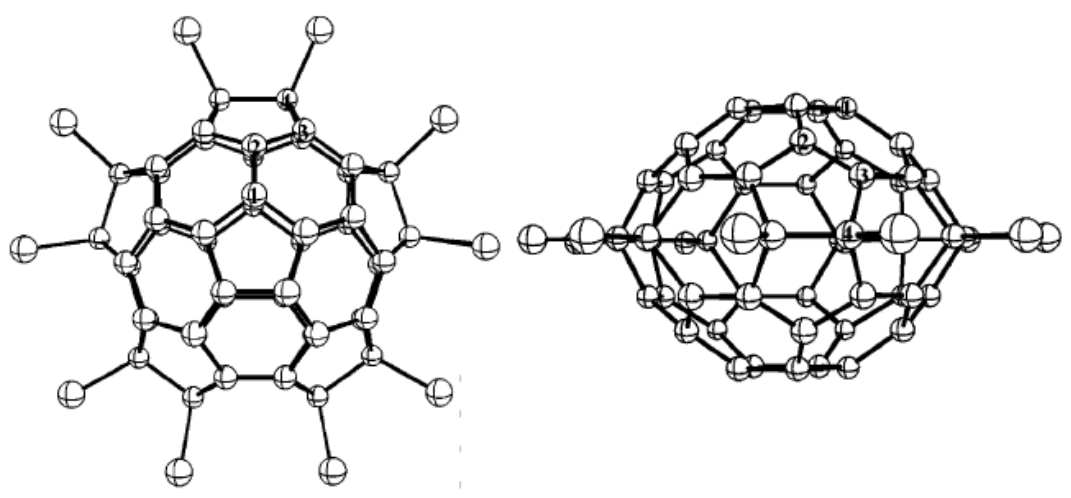

Figure 7. The structure of $\mathrm{C}_{50} \mathrm{Cl}_{10} \cdot{ }^{34}$

The studies of fullerene molecular orbitals made possible to estimate both chemical reactivity of the fullerenes (accompanying the covalent functionalization of carbon framework) and noncovalent binding between fullerenes and various substrates (e.g., protonated porfirines ${ }^{35}$ ).

\subsection{The estimation of fullerene reactivity by indices based on the fullerenes structure}

The earlier works summarized experimental data on the structure of the products of addition to fullerenes have declared ${ }^{36}$ that length of 6.6 bond in $\mathrm{C}_{60}$ is close to average length of $\mathrm{C}=\mathrm{C}$ bond in alkenes, and its chemical properties should be analogous. Structural analysis of $\mathrm{C}_{70}\left(D_{5 h}\right)$ elects the shortest $\boldsymbol{a} \boldsymbol{b}$ and $\boldsymbol{c} \boldsymbol{c}$ bonds (according to PBE/tz2p calculations, 1.400 and $1.394 \AA$, respectively) as the most reactive. ${ }^{37}$ Thus, the bond length is one of the structural parameters that can be used to estimate the reactivity of fullerenes.

Another geometric parameter which can be used for this purpose is the pyramidality angle $\theta_{\mathrm{P}}$ of reaction site being calculated as: ${ }^{38}$

$$
\theta_{\mathrm{P}}=\theta_{\sigma \pi}-90^{\circ}
$$

where $\theta_{\sigma \pi}$ is the angle between the directions of $\sigma$ - and $\pi$-bonds of reaction site. In the case of $s p^{2}$-hybridization, the symmetry axis of $\pi$-orbital is perpendicular to the plane of three $\sigma$-bonds $\left(\theta_{\sigma \pi}=90^{\circ}\right)$ and $\theta_{\mathrm{P}}=0^{\circ}$ (in the case $s p^{3}$-hybridization, $\theta_{\mathrm{P}} \sim 19^{\circ}$ ). 
The nonplanarity of $\mathrm{C}_{60}$ and $\mathrm{C}_{70}$ molecules has been studied with the use of $\theta_{\mathrm{P}}$ values. ${ }^{39}$ It has been shown that local curvature $k$ is linked with the pyramidality angle by following relation:

$$
k \approx 2 \theta_{\mathrm{P}} / a
$$

where $a$ is the average distance between the reaction site and neighboring atoms. The pyramidality angles of each atom in $\mathrm{C}_{60}$ molecule equal to $11.6^{\circ}\left(\mathrm{C}_{60}\right.$ structure has been optimized by HF/3-21G method). ${ }^{39}$ The truth of relation (3) has been confirmed by linear correlation $(r=0.99)$ between $\theta_{P}$ and $k$ values for nonequivalent atoms of $\mathrm{C}_{60}$ and $\mathrm{C}_{70}$ molecules (Figure 8).

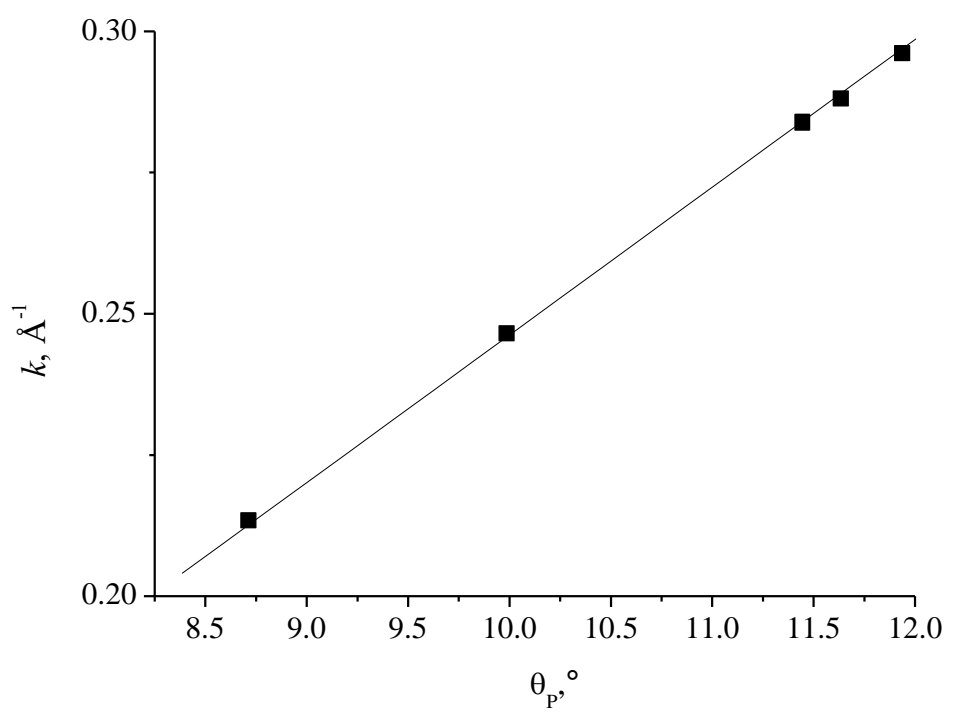

Figure 8. The correlation between pyramidatity angles and carbon surface curvature. ${ }^{39}$

The dependences between heats of reactions of 1,3-dipolar ${ }^{40}$ and radical $^{41}$ addition to fullerenes and curvature indices of reaction sited have been studied. For example, such dependences have been investigated for the model reactions of addition of dipole-molecules ozone $\mathrm{O}_{3}$ (a dipole-molecule of allyl type) and diazomethane $\mathrm{CH}_{2} \mathrm{~N}_{2}$ (a dipole-molecule of propargyl-allenyl type) - to series of fullerenes $\mathrm{C}_{20}\left(C_{i}\right), \mathrm{C}_{36}\left(D_{6 h}\right), \mathrm{C}_{60}\left(I_{h}\right), \mathrm{C}_{70}\left(D_{5 h}\right), \mathrm{C}_{76}\left(D_{2}\right)$, $\mathrm{C}_{24}\left(D_{6}\right), \mathrm{C}_{30}-3\left(C_{2 v}\right)$ and $\mathrm{C}_{40}-38\left(D_{2}\right)$. These typical reactions occur producing 1,2,3-trioxolanes $\mathbf{1 0}$ and pyrazolines $\mathbf{1 1}$ (Scheme 6). 


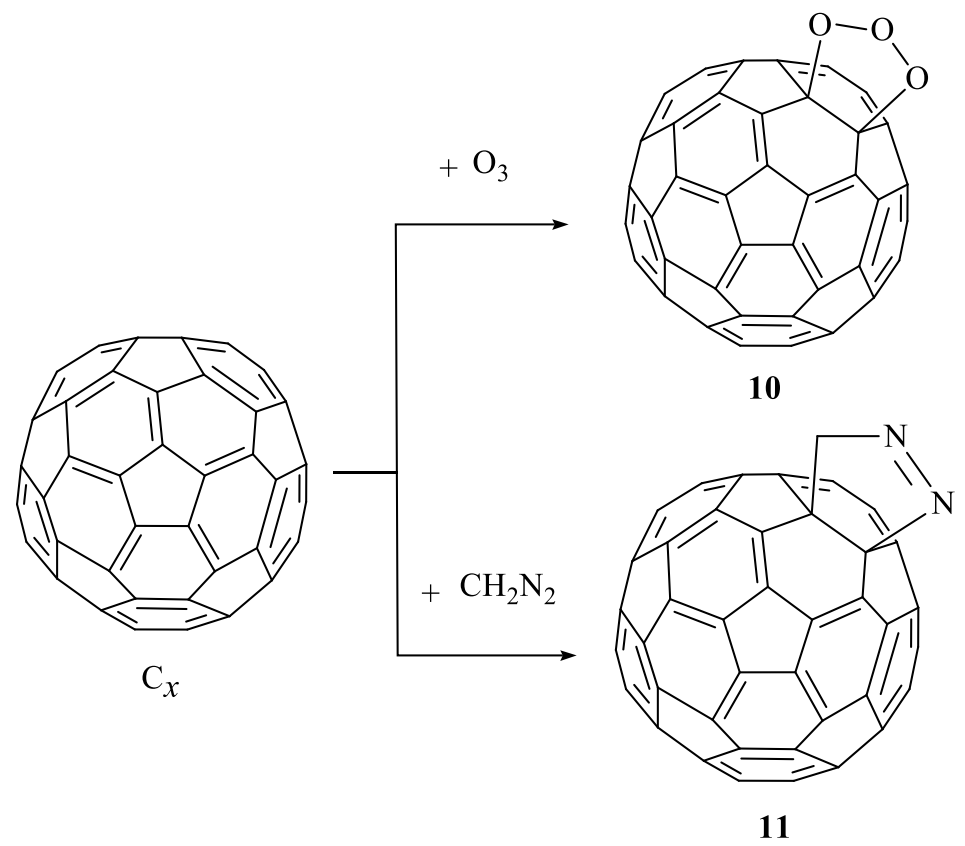

\section{Scheme 6}

Calculated heat effects of reactions ${ }^{40}$ and curvature indices $k$ of reaction sites (Figures 9) are in linear dependences (Figure 10):

$$
\begin{aligned}
& \Delta H_{\mathrm{r}}^{\circ}\left(\mathrm{C}_{n}+\mathrm{O}_{3}\right)=142.4-946.4 k \\
& \Delta H_{\mathrm{r}}^{\circ}\left(\mathrm{C}_{n}+\mathrm{CH}_{2} \mathrm{~N}_{2}\right)=216.0-904.3 k
\end{aligned}
$$

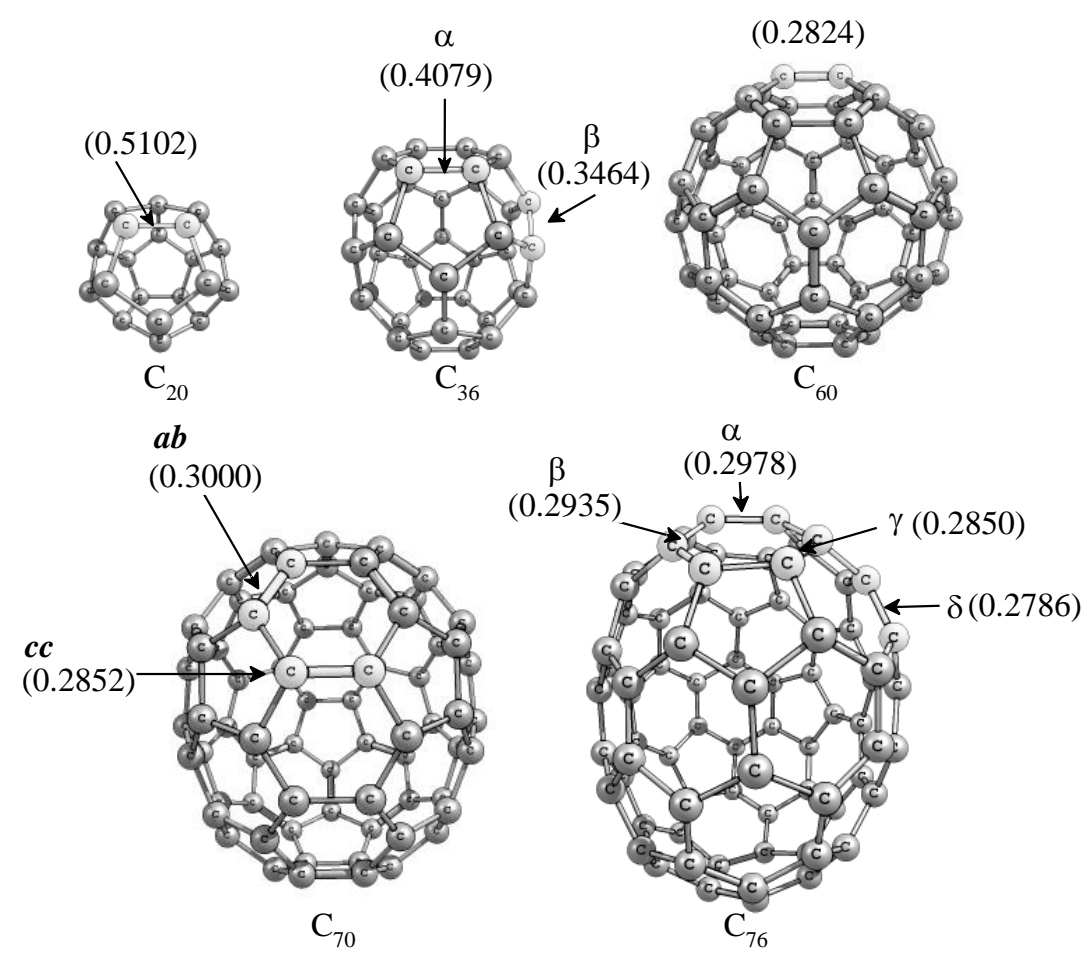




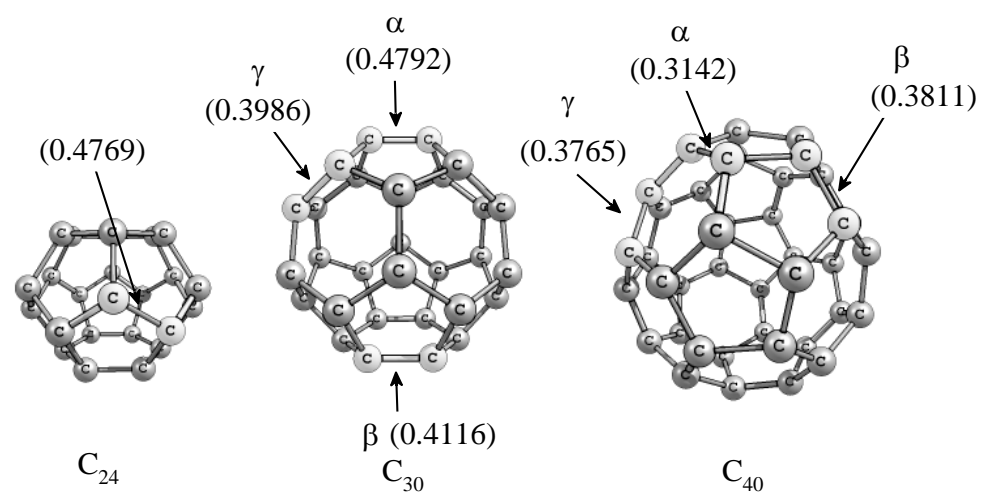

Figure 9. Reaction sites of 1,3-dipolar addition in $\mathrm{C}_{20}\left(C_{i}\right), \mathrm{C}_{36}\left(D_{6 h}\right), \mathrm{C}_{60}\left(I_{h}\right), \mathrm{C}_{70}\left(D_{5 h}\right), \mathrm{C}_{70}$ $\left(D_{2}\right), \mathrm{C}_{24}\left(D_{6}\right), \mathrm{C}_{30}-3\left(C_{2 v}\right)$ and $\mathrm{C}_{40}-38\left(D_{2}\right)$ fullerenes. The $k$ values $\left(\AA^{-1}\right)$ of the most reactive bonds are given in parentheses. ${ }^{40}$

These correlations are characteristic of fullerenes with both isolated $\left(\mathrm{C}_{60}, \mathrm{C}_{70}, \mathrm{C}_{76}\right)$ and shared pentagons $\left(\mathrm{C}_{20}, \mathrm{C}_{24}, \mathrm{C}_{30}, \mathrm{C}_{36}, \mathrm{C}_{40}\right)$. Therefore they can be considered as a common feature of carbon clusters. In the fullerenes obeying the isolated pentagon rule, nonplanar arrangement of $s p^{2}$-hybridized carbon atoms is caused by the presence of a corannulene structural fragment whose geometry (and, consequently, the carbon surface curvature) in this region changes slightly on going from one fullerene to another $\left(k=0.2826-0.3028 \AA^{-1}\right)$. As a consequence, one can expect the formation of adducts at the 6.6 bonds of the corannulene fragments as the most probable channel of the reactions of 1,3-dipolar addition to fullerenes.

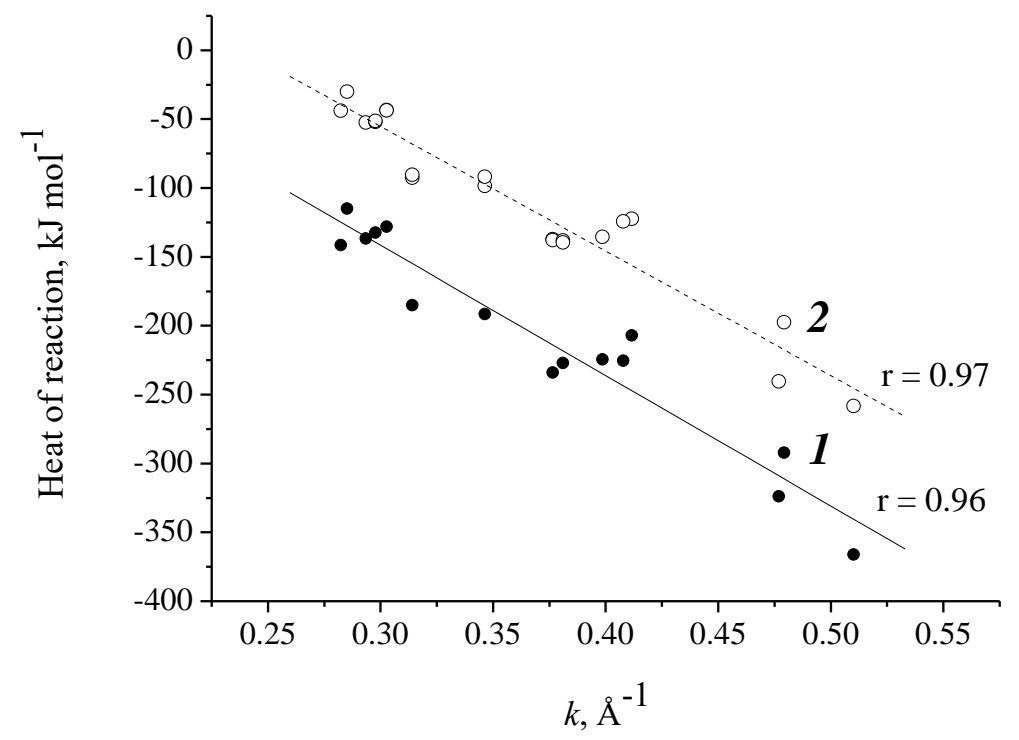

Figure 10. Correlations between heats of addition $\left(\Delta H_{\mathrm{r}}{ }^{\circ}\right)$ of ozone (1) and diazomethane (2) to fullerenes and curvature indices. ${ }^{40}$ 
Then correlations 4 and 5 have been used to analyze the reactivities of hypothetic carbon nanostructures (the giant fullerene $\mathrm{C}_{540}{ }^{40,41}$ and nanocones ${ }^{42}$ ) and the attempt to extend this approach to $\mathrm{C}_{60}$ polar derivatives $\left(\mathrm{C}_{60} \mathrm{O}\right.$ and $\left.\mathrm{C}_{60} \mathrm{~F}_{18}\right)$ has been made. ${ }^{43}$ It has been shown that heat effects of the ozone addition to bonds located in the most curved parts of carbon skeletons are exothermic while the ozone addition to the other bonds is endothermic. Different signs of two reaction channels show the main occurring of the reaction in the most curved areas of nanostructures that makes possible the selective annealing of curved fragments and leads to the formation of apertures in carbon nanostructures (Figures 11 and 12).

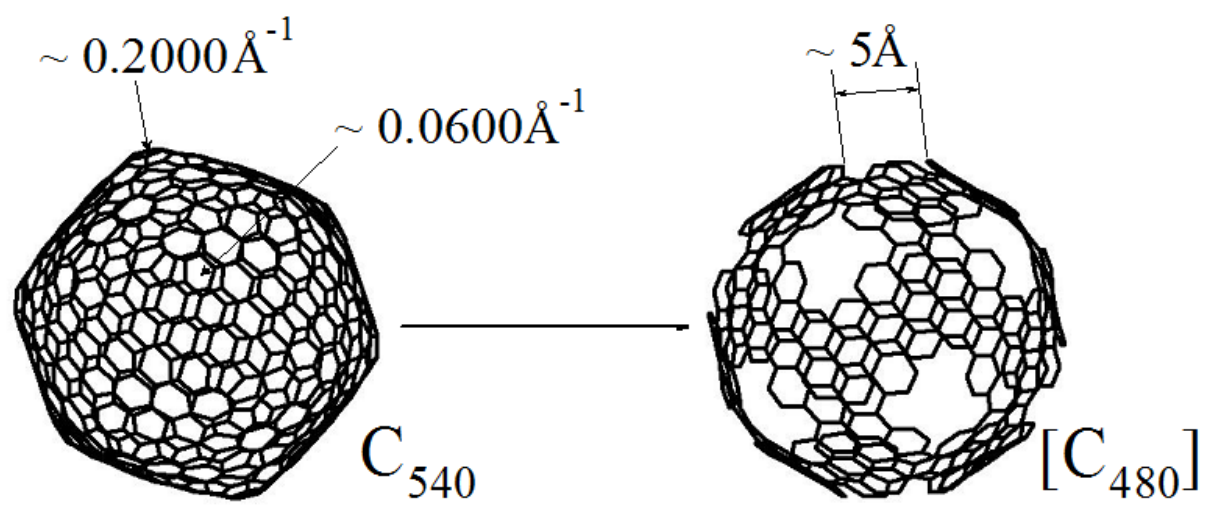

Figure 11. Carbon cages of $\mathrm{C}_{540}$ fullerene and a possible product of ozone annealing of the regions of the $\mathrm{C}_{540}$ surface with the highest curvature. ${ }^{40}$

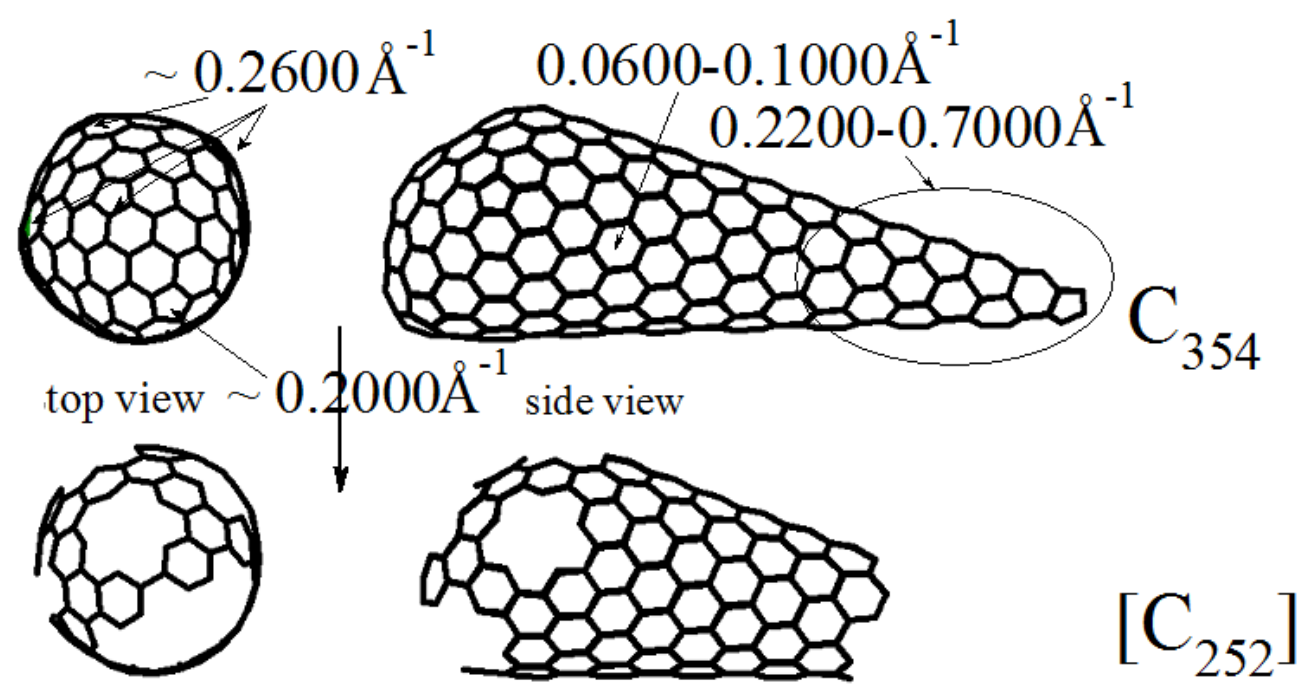

Figure 12. Carbon cages of $\mathrm{C}_{354}$ nanocone and a possible product of ozone annealing of the regions of the $\mathrm{C}_{354}$ surface with the highest curvature. ${ }^{42}$ 
The analysis of pyramidality angles and curvature indices has been used for investigations of single wall carbon nanotubes (SWNT), another carbon allotrope which is similar to fullerenes structurally. In SWNTs without defects $\theta_{P} \sim d^{-1}$ ( $d$ is a diameter of a SWNT), i.e. the constraints of the carbon skeleton are increasing with the decrease in diameters of nanotubes that can be detected with the increase of $\theta_{\mathrm{P}}$ values. ${ }^{44}$ The influence of SWNT diameter on the ozonation of $\mathrm{SWNT}^{45}$ which was studied theoretically (Figure 13) has been confirmed by experimental observation of the main drawing of small-diameter nanotubes in the reaction of ozonolysis. ${ }^{46}$

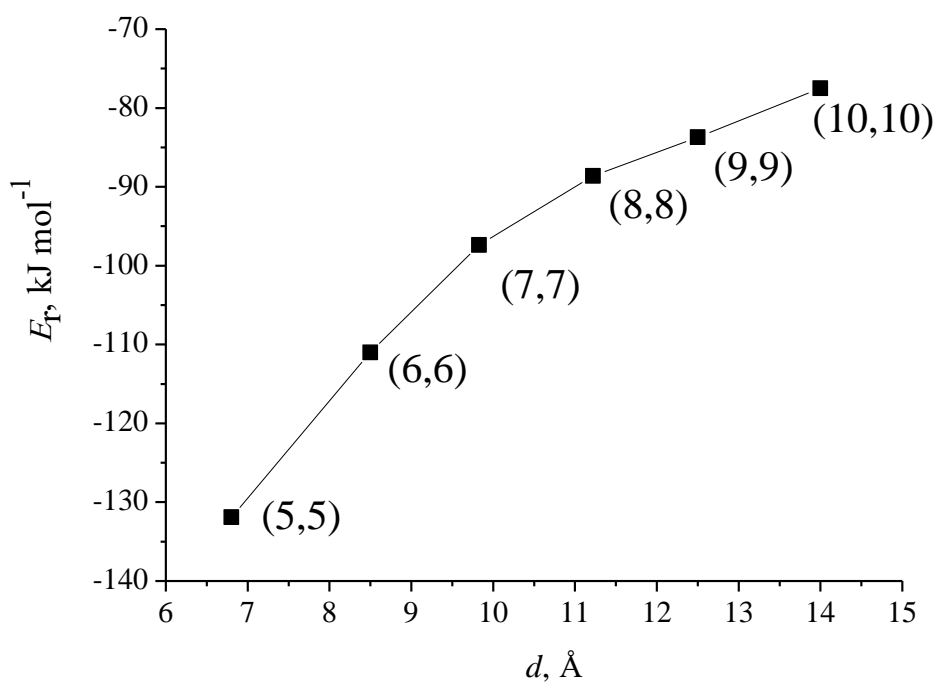

Figure 13. Exothermicity $E_{\mathrm{r}}$ of 1,3 -dipolar addition of ozone to $(n, n)$ nanotubes $v s$. their diameter. $^{44}$

Reactivity of SWNTs is sensitive to the Stone-Wals defects which causes the changes is $\theta_{\mathrm{P}}$ values that is why pyramidality angles are recommended to use as an index of SWNT reactivity. ${ }^{47}$ For example, it has been used for comparative study of reactivity of inner and exterior sidewalls of SWNT towards $\mathrm{H} \bullet$ and $\mathrm{F} \bullet$ radicals: ${ }^{48}$ heat effect of their addition increases with the increase of $\theta_{\mathrm{P}}$ in the case of exterior sidewalls and it decreases in the case of inner sidewalls (Figure 14). The differences of chemical activity of inner and exterior surfaces also have been noted for fullerene cages: ${ }^{49}$ the chemical inertness of inner surface contrasts with high reactivity of exterior surface which is facile for chemical modification via radical and molecular reactions. The differences are caused by the significant energetic expenditures for the distortion of bond lengths and angles upon formation of endo-bonds and exo-bonds. 

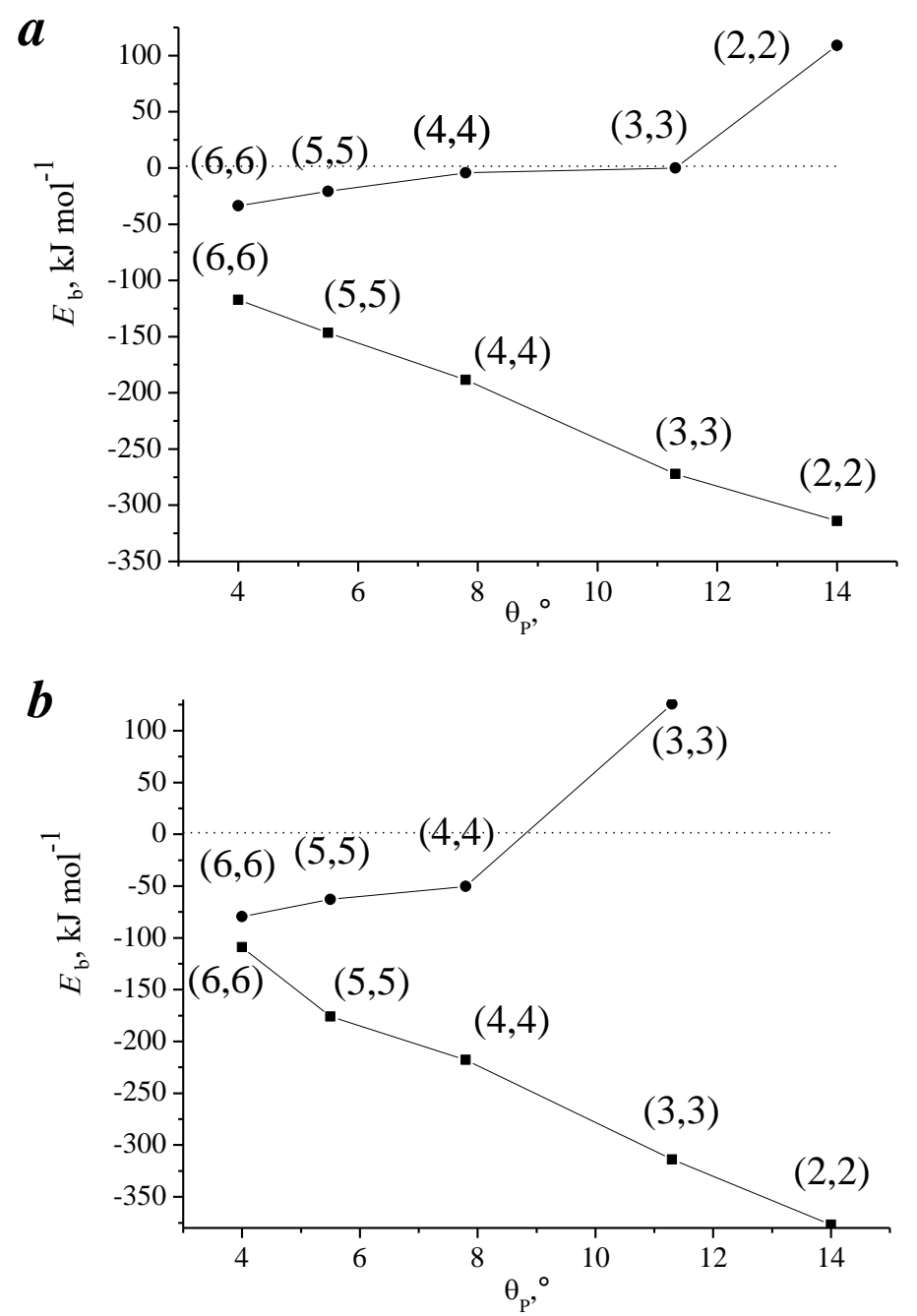

Figure 14. The dependence of exohedral ( $\mathbf{})$ and endohedral ( $\bullet$ ) binding energies $E_{\mathrm{b}}$ calculated by B3LYP/6-31G* method on the pyramidality angles of $(n, n)$ nanotubes $(n=2-6)$ : $\boldsymbol{a}$ - addition of $\mathrm{H} \bullet, \boldsymbol{b}$ - addition of $\mathrm{F} \cdot{ }^{48}$

Reactions of radicals $\mathrm{H} \bullet$ and $\mathrm{CH}_{3} \bullet$ addition to the cap of $(10,10)$ nanotube have been studied by molecular dynamics with Brenner potential and the linear dependence between heats of reactions and pyramidality angles has been found. ${ }^{50}$ It has been also noted that reaction sites whose populations are higher than the average value of population, are characterized with the higher values of $\theta_{\mathrm{P}}$.

Role of the curvature and pyramidality angles for estimation of reactivity and stability not only of fullerenes but another framework nanostructures based on the metal oxides has been considered. ${ }^{51}$ Theoretical analysis shows that nanoparticles containing the regions of negative curvature alternated with those of positive curvature should be the most stable, e.g., nanoclusters of icosahedral symmetry in Figure 15. 

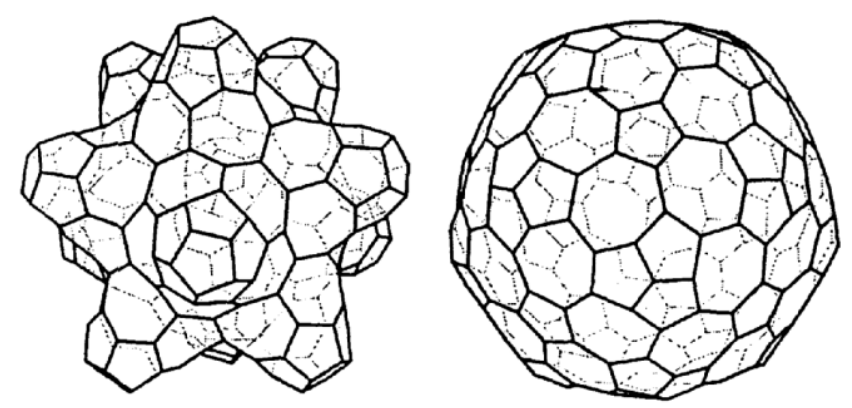

Figure 15. Hypothetical fullerene-like nanoclusters constructed with 72 pentagons (regions of positive curvature) and 60 heptagons (regions of negative curvature). ${ }^{51}$

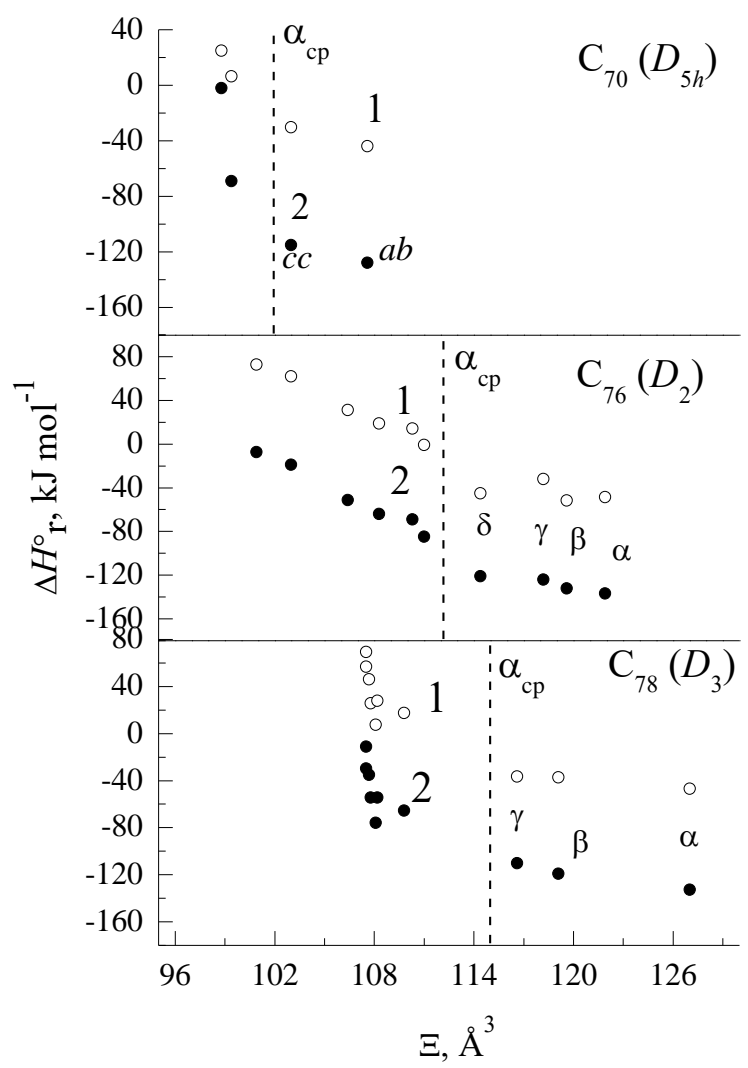

Figure 16. Heats $\Delta H_{\mathrm{r}}{ }^{\circ}$ of addition of (1) diazomethane and (2) ozone to fullerenes $\left(\Delta H_{\mathrm{r}}{ }^{\circ}\right) v s$. polarizability indices of 6.6 bonds. ${ }^{52}$

A new theoretical approach based on the polarizability indices ${ }^{52}$ adjoins the 'geometrical' methods of estimation of fullerenes reactivity. The conformity between the ellipsoid of fullerene polarizability and the model ellipsoid circumscribed about a fullerene cage underlies this approach. It allows calculating the polarizability in the direction of each reaction site in a fullerene molecule ( $\Xi$ index). 
The procedure for estimating the reactivity of nonequivalent 6.6 bonds of higher fullerenes was tested using the reaction of 1,3-dipolar addition of ozone and diazomethane (Scheme 6). On the initial steps of these reactions the formation of prereactionary complexes takes place. Such complexes are stabilized, as it was shown for ozone addition to $\mathrm{C}_{60},{ }^{53}$ by the dispersion interaction between the reactants which depends mainly on the fullerene polarizability.

The heats of the reactions of addition of $\mathrm{O}_{3}$ and $\mathrm{CH}_{2} \mathrm{~N}_{2}$ to nonequivalent 6.6 bonds of $\mathrm{C}_{70}$ $\left(D_{5 h}\right), \mathrm{C}_{76}\left(D_{2}\right)$ and $\mathrm{C}_{78}\left(D_{3}\right)$ increase with an increase in the polarizability index $\Xi$ of the bond to which these molecules are attached (Figure 16). Applying the criterion $\Xi>\alpha_{\mathrm{av}}\left(\alpha_{\mathrm{av}}\right.$ is the average polarizability of a fullerene) to the 6.6 bonds of fullerenes makes it possible to reveal the bonds most reactive to ozone (diazomethane) in the polar hexagons (located near the poles of the fullerene molecules) and the hexagons adjacent to them.

The efficient use of polarizability to estimation of fullerenes activity in chemical processes ${ }^{52}$ and the role of polarizability in the quenching of electronically excited states of various matters by $\mathrm{C}_{60}$ and $\mathrm{C}_{70}{ }^{54}$ elucidate the common nature of chemical and photophysical processes which fullerenes take part in. Theoretical studies on the polarizabilty and hyperpolarizability of endofullerenes are important for understanding of the endohedral complexes reactitity. And the first steps in this direction allowed predicting some unusual properties, such as the long range ion bond in $\mathrm{Na} @ \mathrm{C}_{60} \ldots \mathrm{F} @ \mathrm{C}_{60}$ dimer $^{55}$ and exaltation of polarizability of endohedral complexes $\mathrm{X} @ \mathrm{C}_{n}(n=20,24,28,36,50,60 ; \mathrm{X}$ is an a noble gas atom $) .{ }^{56}$

\section{Conclusion}

Thus, in the paper various theoretical approaches to estimation of fullerenes reactivity have been discussed. They can be conditionally divided in four groups (quantum chemical calculations of thermodynamic and kinetic parameters; the population analysis; the analysis of molecular orbitals; use of indices linked with the structure of fullerenes). Among them we can elect both approaches that have been used for the other organic compounds earlier (e.g., comparative bond orders analysis) and approaches being used for fullerenes and nanotubes only (curvature and polarizability indices).

\section{Acknowledgements}

This work was supported by the Presidium of the Russian Academy of Sciences (program no. 22 "Foundations of Basic Research of Nanotechnologies and Nanomaterials"). 


\section{References}

1. Diederich, F.; Ettl, R.; Rubin, Y.; Whetten, R. L.; Beck, R.; Alvarez, M.; Anz, S.; Sensharma, D.; Wudl, F.; Khemani, K. C.; Koch, A. Science. 1991, 252, 548.

2. Shestakov, A. F. Rossiiskii Khimicheskii Zhurnal 2007, 51, 121 (in Russian).

3. Sabirov, D. Sh.; Khursan, S. L.; Bulgakov, R. G. J. Mol. Graph. Model. 2008, 27, 124.

4. Sabirov, D. Sh.; Khursan, S. L.; Bulgakov, R. G. Fullerenes, Nanotubes and Carbon Nanostructures 2008, 16, 534.

5. Sabirov, D. Sh.; Bulgakov, R. G.; Galimov, D. I.; Khursan, S. L. 'Peroxides-2009'. Proceedings of Russian Scientific Conference on the Chemical Kinetics of Oxidation Processes, Ufa, Russia, July 6-10, 2009: 130.

6. Shang, Zh.; Pan, Y.; Cai, Z.; Zhao, X.; Tang, A. J. Phys. Chem. A 2000, 104, 1915.

7. Solà, M.; Mestres, J.; Martí, J.; Duran, M. Chem. Phys. Lett. 1994, 231, 325.

8. Cases, M.; Duran, M.; Mestres, J.; Martín, N.; Solà, M. J. Org. Chem. 2001, 66, 433.

9. Alvarez, A.; Ochoa, E.; Verdecia, Y.; Suárez, M.; Solá, M.; Martín, N. J. Org. Chem. 2005, $70,3256$.

10. Kavitha, K.; Venuvanalingam, P. J. Org. Chem. 2005, 70, 5426.

11. Evlampieva, N. P.; Yakimanskii, A. V.; Dobroumov, A. V.; Nazarova, O. V.; Pashkov, Yu. B.; Panarin, E. F.; Ryumtsev, E. I. Russ. J. Gen. Chem. 2005, 75, 751.

12. Tuktarov, A. R.; Akhmetov, A. R.; Sabirov, D. Sh.; Khalilov, L. M.; Ibragimov, A. G.; Dzhemilev, U. M. Russ. Chem. Bull., Int. Ed. 2009, 58, 1724.

13. Bulgakov, R. G.; Sabirov, D. Sh.; Khursan, S. L.; Razumovskii, S. D. Mendeleev Commun. 2008, 18, 307.

14. Sabirov, D. Sh.; Bulgakov, R. G.; Khursan, S. L. Mendeleev Commun. 2010, 20, 231.

15. D'yachkov, P. N. Russ. J. Inorg. Chem. 2001, 46, 92.

16. Ueno, Yu.; Saito, S. Physica E 2007, 40, 285.

17. Korona, T.; Hesselmann, A.; Dodziuk, H. J. Chem. Theory Comput. 2009, 5, 1585.

18. Rabilloud, F. J. Phys. Chem. A 2010, 114, 7241.

19. Wang, Q.; Sun, Q.; Jena, P.; Kawazoe, Y. J. Chem. Theory Comput. 2009, 5, 374.

20. Sharma, H.; Garg, I.; Dharamvir, K.; Jindal, V. K. J. Phys. Chem. C 2010, 114, 9153.

21. Xu, L.; Shao, X.; Cai, W. J. Phys. Chem. A 2009, 113, 10839.

22. Zhao, H.-L.; Pan, F.; Liu, Z. H.; Tao, Ch.-Yu.; Gan, L.-H. Comput. Theor. Chem. 2011, 963, 115.

23. Jayasekharan, T.; Ghanty, T. K. J. Phys. Chem. C 2010, 114, 8787.

24. Jin, P.; Hao, C.; Gao, Zh.; Zhang, Sh. B.; Chen, Zh. J. Phys. Chem. A 2009, 113, 11613.

25. Osawa, E. Kagaku 1970, 25, 854.

26. Bochvar, D. A.; Galpern, E. G. Dokl. Akad. Nauk 1973, 209, 610 (in Russian).

27. (a) Sheka, E. F.; Zaets, V. A. Zhurn. Fiz. Khimii 2005, 79, 2250. (b) Sheka, E. Int. J. Quant. Chem. 2004, 100, 375 . 
28. Sabirov, D. Sh.; Bulgakov, R. G.; Ponomareva, Yu. G. 'Lomonosov-2008', $14^{\text {th }}$ International Conference on Fundamental Sciences, Moscow, Russia, April 14-18, 2008: 672.

29. Hirsch, A. Topics Cur. Chem. 1999, 199, 1.

30. Bühl, M.; Hirsch, A. Chem. Rev. 2001, 101, 1153.

31. Estrada-Salas, R. E.; Valladares, A. A. J. Phys. Chem. A 2009, 113, 10299.

32. Lu, X.; Chen, Z. F.; Thiel, W.; Schleyer, P. v. R.; Huang, R. B.; Zheng, L. S. J. Am. Chem. Soc. 2004, 126, 14871.

33. Lu, X.; Chen, Zh. Chem. Rev. 2005, 105, 3643.

34. Xie, S.-Yu.; Gao, F.; Lu, X.; Huang, R.-B.; Wang, Ch.-R.; Zhang, X.; Liu, M.-L.; Deng, Sh.L.; Zheng, L.-S. Science 2004, 304, 699.

35. Jung, S.; Seo, J.; Shin, S. K. J. Phys. Chem. A 2010, 114, 11376.

36. Sokolov, V. I.; Stankevich, I. V. Russ. Chem. Rev. 1993, 62, 419.

37. Zverev, V. V.; Kovalenko, V. I. Russ. J. Phys. Chem A 2006, 80, 99.

38. Haddon, R. C. Science 1993, 261, 1545.

39. Haddon, R. C. J. Am. Chem. Soc. 1997, 119, 1797.

40. Sabirov, D. Sh.; Khursan, S. L.; Bulgakov, R. G. Russ. Chem. Bull., Int. Ed. 2008, 57, 2520.

41. Sabirov, D. Sh.; Bulgakov, R. G. Comput. Theor. Chem. 2011, 963, 185.

42. Sabirov, D. Sh.; Bulgakov, R. G.; Khursan, S. L. 'Peroxides-2009', Russian Scientific Conference on the Chemical Kinetics of Oxidation Processes, Ufa, Russia, July 6-10, 2009: 128.

43. Sabirov, D. Sh.; Bulgakov, R. G. Fullerenes, Nanotubes Carbon Nanostruct. 2010, $18,455$.

44. Niyogi, S.; Hamon, M. A.; Hu, H.; Zhao, B.; Bhowmik, P.; Sen, R.; Itkis, M. E.; Haddon, R. C. Acc. Chem. Res. 2002, 35, 1105.

45. Lu, X.; Tian, F.; Xu, X.; Wang, N.; Zhang, Q. J. Am. Chem. Soc. 2003, 125, 10459.

46. Banerjee, S.; Wong, S. S. Nano Lett. 2004, 4, 1445.

47. Akdim, B.; Kar, T.; Duan, X.; Pachter, R. Chem. Phys. Lett. 2007, 445, 281.

48. Chen, Zh.; Thiel, W.; Hirsch, A. Chem. Phys. Chem. 2003, 4, 93.

49. Buchachenko, A. L.; Breslavskaya, N. N. Russ. Chem. Bull., Int. Ed. 2005, 54, 51.

50. Astakhova, T. Yu.; Vinogradov, G. A.; Gurin, O. D.; Menon, M. Russ. Chem. Bull., Int. Ed. 2002, 51, 764.

51. Müller, A.; Roy, S. Russ. Chem. Rev. 2002, 71, 981.

52. Sabirov, D. Sh.; Bulgakov, R. G.; Khursan, S. L.; Dzhemilev, U. M. Doklady Phys. Chem. 2009, 425, 54.

53. Sabirov, D. Sh.; Khursan, S. L.; Bulgakov, R. G. Vestn. Bashkirsk. Univ. 2007, 12(2), 18 (in Russian).

54. Bulgakov, R. G.; Galimov, D. I.; Sabirov, D. Sh. JETP Lett. 2007, 85, 632.

55. Ma, F.; Li, Z.-R.; Zhou, Z.-J.; Wu, D.; Li, Y.; Wang, Y.-F.; Li, Z.-Sh. J. Phys. Chem. C 2010, 114, 11242.

56. Sabirov, D. Sh.; Bulgakov, R. G. JETP Lett. 2010, 92, 662. 


\section{Authors' Biographies}

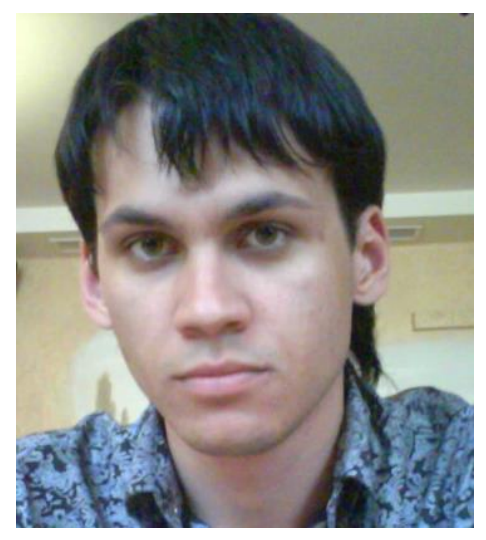

Denis Sh. Sabirov (born in 1984) is a head scientific worker of Physical Chemistry Problems Laboratory (Institute of Petrochemistry and Catalysis, Russian Academy of Sciences). He became a candidate of sciences (in the fields of two sciences: "Mathematical and Quantum Chemistry" and "Physical Chemistry") in 2009 year (the theme of the thesis is "Intermediates of fullerenes ozonolysis and fullerenes reactivity in 1,3-dipolar addition reactions"). His scientific interests include density functional theory calculations, reaction mechanisms, theory of reactivity, symmetry of molecular systems, and use of chemiluminescence for investigation of reaction mechanisms.

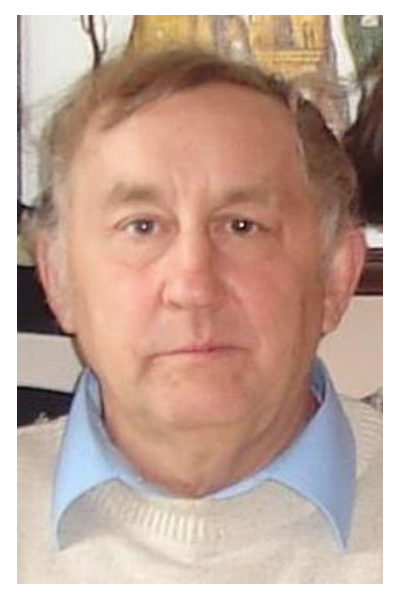

Prof. Ramil G. Bulgakov (born in 1943) is the chief of Physical Chemistry Problems Laboratory (Institute of Petrochemistry and Catalysis, Russian Academy of Sciences). He is well-known specialist in the fields of generation and deactivation of electronically excited states of fullerenes and lanthanide compounds in redox-reactions, oxy-functionalization of fullerenes and lanthanide coordination catalysis. 


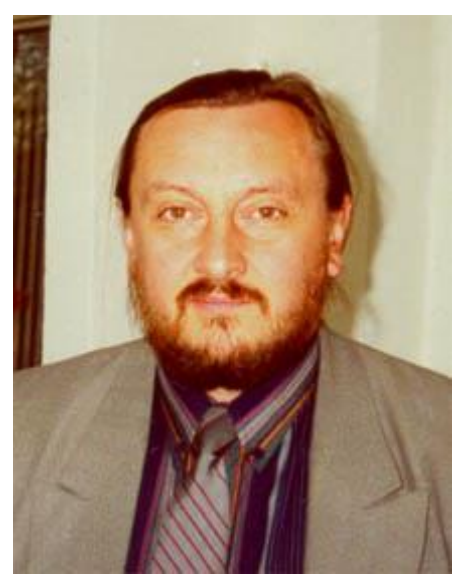

Prof. Sergey L. Khursan (born in 1961) is a chief scientific worker of the Institute of Organic Chemistry, Ufa Scientific Centre of Russian Academy of Sciences. His scientific interests are chemistry of oxidative processes, ozonation of organic compounds, thermochemistry, quantum chemistry, chemical kinetics. 